\title{
HEGEMONY, SOCIAL CLASS AND STYLISATION
}

\author{
Ben Rampton
}

\begin{abstract}
${ }^{1}$
Focusing on issues of class identity, this paper explores the relationship between sociolinguistics and Raymond Williams' view of hegemony as "relations of domination and subordination... [that saturate] the whole process of living...: Our senses and assignments of energy, our shaping perceptions of ourselves and our world" (1977: 109-110). It assesses the kinds of insight afforded in both variationist and interactional sociolinguistics, and then turns to an analysis of London adolescents putting on exaggerated 'posh' and 'Cockney' accents in situated interaction. Underpinning the contingencies of particular instances, there was a set of well-established dualisms shaped in relations of class inequality (high vs low, mind vs body, reason vs emotion), and the resonance and reach of these was attested both in corporeal performance and in the fantastical grotesque. Can theories of interactional 'identity projection' do justice to this, or can sociolinguistics accommodate the cultural analyst's wider concern for 'subjectivity'? The paper looks at ways of drawing these perspectives together, and concludes with an emphatic rejection of claims that in late modernity, class identities are losing their significance.
\end{abstract}

Keywords: Class, Inequality, Hegemony, Stylisation, Interactional sociolinguistics

\section{Introduction}

This paper examines the effects of class hierarchy on the action and consciousness of specific individuals, looking towards Raymond Williams' view of 'hegemony' as "relations of domination and subordination... [that saturate] the whole process of living...: our senses and assignments of energy, our shaping perceptions of ourselves and our world" (1977: 109-110). More generally, the paper seeks to engage critically with claims that in

${ }^{1}$ In this paper, I am enormously indebted to other members of the Research Group on Language, Power and Identity (Jan Blommaert, Jim Collins, Monica Heller, Stef Slembrouck \& Jef Verschueren), and for inputs they may not be aware of, I would also like to thank Roxy Harris, Annie Gillett, Helen Lucey and Diane Reay. I am also grateful to the participants and organisers of several forums where I received invaluable feedback on earlier versions of the paper: 'Sociolinguistics Symposium 14' (Gent), the seminar on 'Semiotics: Culture in Context' (University of Chicago, Dept of Anthropology), and the Workshop on 'Acts of Identity' (Freiburg, where I benefited a lot from Helga Kotthoff's insightful commentary). I am also very grateful to the FWO (Belgian Science Foundation - Flanders) for financial support for the LPI group, and to the Economic and Social Research Council for supporting the research project that this paper draws on (Project R 00023 6602). 
contemporary Britain (and elsewhere), social class identities are declining in significance. The 'demise of class' idea is often linked in its most recent versions to the economic restructuring attendant on globalization, ${ }^{2}$ and it runs with a view that ethnicity and gender are now more salient bases for political mobilisation (e.g. Bradley 1996: 105,136). But although my study focuses on a multi-ethnic peergroup in a 'global city' (London), even a brief look at accent variation points to enduring processes of class reproduction, while a closer analysis of interactional discourse points to an active and insistent class consciousness. Admittedly, as an explicit talking point among the informants in this study, class did seem to be much less of an issue than ethnicity and gender, but in the flow of everyday activity, these adolescents repeatedly linked the people, actions and events around them to images of class hierarchy through spontaneous stylised performances in which exaggerated posh and vernacular London accents were a salient ingredient.

Another of my objectives is to explore the possibilities and limits of the perspectives on hegemony and class offered in interactional sociolinguistics, my main methodological resource here (Gumperz 1982; Rampton 2001), and in variationist dialectology, to which I also refer (Labov 1972; Eckert 2000). ${ }^{3}$ In fact, discussion of these possibilities and limits can provide us with a useful point of departure.

\section{Class and sociolinguistics}

In discussions of hegemony and in cultural theories of class more generally (e.g. Thompson 1963; Willis 1977; Foley 1990), there is a great deal of interest in the dynamic relationship between class experience and class consciousness. What insight into this can we gain from variationist and interactional sociolinguists?

Class has long been a central social factor addressed in the variationist/quantitative paradigm, and among other things, it has repeatedly found that in class-stratified societies, the social group stratification of speech is mirrored in style-stratification, that accent differences between/across class-groups-in-society-as-a-whole are 'echoed' within the speech repertoire of individuals, their speech becoming more like the speech of high-placed social groups as situations get more formal (Labov 1972; Bell 1984). Potentially, this is impressive testimony to class reproduction, large-scale stratification being inscribed even into the apparently flexible conduct of individuals, and this has sometimes been linked to Bourdieu's notion of 'habitus', a pre-conscious disposition to hear and speak in class and gender specific ways inculcated into the individual through long-term experience of the purchase that their language resources provide in different kinds of setting (Bourdieu 1977, 1991: Part 1; Woolard 1985). But for the most part, variationist linguists have been much

${ }^{2}$ E.g. the decline of area-based manufacturing industries like mining, steel and shipbuilding, the growth of the services sector, and with women and black people almost $50 \%$ of all manual labour, a major shift in the demographic composition of the work force (Abercrombie \& Warde et al 2000: 167; Gilroy 1987: 19; Reay 1998.

${ }^{3}$ Class has obviously been a major concern in branches of sociolinguistics that I don't discuss here (see e.g. Bernstein's work, and research on public debates about language (Crowley 1989; Mugglestone 1995)). 
more interested in linguistic than social change, and social structure has been treated as a given, as an independent variable, rather than as something to be explained (Cameron 1992). In Hymes' judgement, variationist research might have done more to address the links between language and class than other branches of sociolinguistics, but for the most part, as elsewhere, "as a lived reality [it] has hardly begun to appear as a focus of inquiry in its own right" (1996: 73; Coupland 2001b: 13).

One major exception to this is to be found in Eckert (2000), which explains the well-established correlation between linguistic variation and occupational status by combining Bourdieurian practice theory with a vivid ethnography of adolescent taste, gender-relations, school-orientation, recreation and geographic mobility, all within a cultural space marked out by two polar style groups, 'jocks' (on a middle class trajectory) and 'burnouts' (heading for the proletariat). The lived reality of what analysts call 'class' consists of a plurality of more local activities and category memberships differing markedly in their alignment to what teachers, schools, peers and adults value, and in the work of Eckert and other ethnographically sensitive variationists, empirical explanation of correlational language- $\&$-class findings ${ }^{4}$ requires (a) cultural description centred on 'midlevel' units like networks and communities of practice, and (b) theories of how such units articulate with the macro processes of the economy (see also L. Milroy 1980: Ch 1; Milroy \& Milroy 1992; J. Milroy 1992: 214-220). So for the most part, class is regarded as an analyst's abstract diagnostic, consequential in its material effects but remote nevertheless from the symbolic meanings that linguistic variants have for their users (Eckert 2000: 14, 222). ${ }^{5}$

Admittedly, Eckert's theoretical rationale has a lot in common with my own position in much of what follows: Adolescents' reflexivity and critical analysis of the processes they're involved in is deemed important, and their comments on language (and other semiotic phenomena) being "elite or working-class, educated or not, prissy or tough" (2000: 43) are identified as part of this. Nevertheless, the variationist paradigm has traditionally shown little interest in how socially marked language forms can be used either as strategic interventions in, or as reflexive comments on, the interactional unfolding of social relations, and to maximise the relevance of her re-theorisation of variationist findings, Eckert's descriptions of language data are quantitative rather than discourse analytic, consisting of aggregate overviews of the speech production in sociolinguistic interviews, not close-up portraits of actors using particular forms for social positioning within the interactive contingencies of the situated moment. In sum, even when it is ethnographically grounded and theoretically tuned to the possibilities of critical agency, quantitative correlation leads variationist research to empirical descriptions in which language appears as a reflection of 'social being', not as an element of 'social consciousness'.

This is not to say that the quantitative paradigm pays no attention at all to consciousness of class. Elsewhere, Labov and many others have followed Lambert and

${ }^{4}$ Attention to mid-level units will also often produce stronger/better correlations (see Milroy 1980).

5 Indeed, in suggesting that while notions of 'class' remain largely obscure to adolescents, their volitional activity systematically draws them into unequal positions of power and privilege, it's a valuable account of class hegemony in one of its senses (see the Introduction). 
attempted to get close to the way people feel about accents by asking them to listen and respond to carefully selected recordings of language variation, the logic being that this "reveal[s] judges' more private reactions to the contrasting group than direct attitude questionnaires do" (Lambert 1972: 337; Labov 1972). Procedures of this kind have pointed to extensive linguistic insecurity among people with lower class status; they have established in very broad terms that whereas standard varieties strike listeners as intelligent, efficient, educated and so on, non-standard speech often sounds more trustworthy and sociable; and I shall refer to this research again in Section 5. But the ecological validity of such findings has been a serious worry among social psychologists of language for a long time (e.g. Giles \& Ryan 1982). Semantic differential questionnaires, for example, make listeners translate their feelings into the language and media of the academic middle class; the recordings used in elicitation involve a great deal of semiotic reduction; and there is nothing of the grimace, wink, mental note or verbal riposte that speakers often make in interaction face-to-face (see Garrett, Coupland \& Williams 1999: 323 for an excellent assessment). In the ethnography of communication, there's ample evidence how small shifts in accent can help to politicise a suggestion, or racialise a request (see e.g. Bauman \& Briggs 1990; Rampton 1995), but none of the analytic resources in the quantitative/variationist paradigm can capture such nuances. Overall, we are forced to conclude that in the social fields they describe, there might be much sharper, more active class consciousness than quantitative work suggests, and at this point we should turn to discourse-oriented sociolinguistics.

The depth and extent to which interactional, ethnographic and discourse-oriented sociolinguistics have actually engaged with class identity might be questioned on both ontological ${ }^{6}$ and historical grounds, ${ }^{7}$ but in principle anyway, their analytic tools are potentially much more sensitive to the ways in which social class can operate on-line as a locally activated, emic category. Studies of language and ethnicity often show, for example, a switch of speech style can conjure ingroup solidarities (e.g. Gumperz 1982), and if the focus shifts from ethnic to classed speech styles, it should be certainly possible to study social class as a strategic interactional identity projection, an identity projection that proposes affiliative or oppositional lines of engagement in moments of, for example, conflicting interest - class as practical consciousness on-line in dialectical moments of

\footnotetext{
${ }^{6}$ In the ethnography of communication \& linguistic anthropology, there is a substantial body of work looking at how group-specific communicative practices lead to effects that analysts can construe in loosely class terms. But for Hymes, anyway, the analytic key in much of this work has been 'difference' rather than 'domination', and the stark possibility that e.g. educational failure might in some way represent the logical destiny of cultural and linguistic dispositions shaped in subordination has generally been emphatically rejected: "[ $\mathrm{t}]$ he conception of differences among peoples, languages and ways of life remained the traditional anthropological one of equivalence... Differential access to resources there might be, but so far as ability was concerned, class has no cost" (Hymes 1996: 187-8; Foley 1990: 184; Bourdieu 1991: 53).

${ }^{7}$ There is a significant body of work looking at "resistance or counter-hegemonic discourses [in] the expressive genres - songs, speeches, poems, conversations - of working class and minority speakers in core and peripheral capitalism" (Gal 1989: 360), though it is open to question how far 'social class' actually serves as a term in folk analysis, as a locally potent identity that could resonate in collective mobilisation. Certainly in the USA, which is the main base for this kind of ethnographic sociolinguistics, race and gender generally come more readily to hand in everyday analyses of inequality than class (see Ortner 1991: 169; Bradley 1996: 182-3; Urcioli 1996).
} 
struggle (see Clark 2003 for some excellent exemplification). This would be broadly consistent with E. P. Thompson's argument that social class is the "the outcome of political and cultural skills", that "agency lies, not in class [in the abstract], but in [people]", and that "politics is often about exactly this: How will class happen, where will the line be drawn" (Thompson 1978: 296). At the same time, though, there may be grounds for both qualifying the scope of the claims discourse analysis might make, and for raising its ambitions, if we consider Williams' notion of hegemony as "the lived dominance of particular classes", "constitut[ing] a sense of reality... a sense of absolute because experienced reality beyond which it is very difficult for most members of the society to move, in most areas of their lives" (Williams 1977: 109-110).

Discourse analyses of interactional self-positioning generally (a) focus on the situated use of specific linguistic structures, (b) look beyond the encounter on hand for the wider social images/categories that these structures appear to invoke, and then (c) attend to the pragmatic impact that the emerging social index has in interaction (see e.g. Antaki \& Widdicombe 1998: 3; Rampton 1999a). The second element in this set of concerns - the wider set of images/ representations/identities that an item evokes - are often of less interest than their pragmatic relevance and effect, and indeed in some cases, such extrinsicallyderived 'social meanings' are regarded as irrelevant to the local interaction, being little more than unwarranted analytic attributions (e.g. Antaki 1998). The time-frame is interactional, and effects, conflicts and change are studied within the moment-to-moment unfolding of interpersonal encounters. In contrast, in cultural studies, rather than the agent's social self-positioning per se, there is much more of an interest in the manner and extent to which agents reproduce, recognise and/or resist the social principles (hitherto) structuring their consciousness, and analysis often moves from (a) a focal interest in expressive texts, artefacts and genres, to (b) an engagement with the wider cultural conventions and socio-political relations that they are embedded in, to (c) an interpretation of the more enduring sensibilities and 'structures of feeling' that are articulated in these texts, artefacts and genres (Williams 1977: 128-135; Eagleton 1984: 110). Whereas interactional analysis tends to treat (b) as (mere) 'resources', cultural studies pays extensive attention to the circumambient relations, conventions and imageries that specific expressive works are set within/against. Its time-frame is historical, and it attends to the emergence, ascendance and decline of the social formations and cultural movements that give shape to particular structures of feeling. So in the first instance, if we are interested in Williams' conceptualisation of hegemony and in the classed and enduring sensibilities it points to, the comparison with cultural studies reminds us that if we went too far equating it with interactional positioning, we might end up trivialising social class, exaggerating the power of individual agents, even succumbing to market ideologies which treat class position as a matter of individual will, effort and enterprise.

Admittedly, strictures of this kind might be more relevant to e.g. conversation analysts than to linguistic anthropologists. One of the linguistic anthropologist's first instincts is to contextualise specific strips of activity within larger social formations, and an interaction-based study of class would seem distinctly 'thin' if it wasn't supplemented with historical and/or ethnographic analysis. But when Williams and others insist that in a vital respect class hegemony is a subjective condition (Skeggs 1998: 9; Hey 1997; Reay 1998), they raise questions that are less commonly addressed, and suggest that as well as turning to the larger processes that frame it, we actually take another, 'deeper', look at talk 
itself. 'Structures of feeling' are less flexible than the motile identity projections that are typically studied in interactional discourse analysis, and if we want to engage with hegemony in Williams' sense, our analyses of interaction need also to ask: How far is class somehow structuring the subjectivity at work in the discourse we witness? To what extent are the participants' actions reproducing, recognising and/or resisting the class principles structuring their everyday sense of the world?

We can summarise this methodological discussion of language and class as follows:

1. although social class often figures in variationist research as little more than "a parameter of change and statistical difference" (Hymes 1996: 73), quantitative findings on dialect variation provide suggestive evidence of class habitus, and there is recent work that situates this in "lived realities" that produce class outcomes (Eckert). But the linguistic display of class consciousness in everyday interaction remains methodologically inaccessible within the quantitative paradigm.

2. Sociolinguistic interaction analysis provides us with a chance to study consciousness of class close-up in action. Even so, if we want to engage with hegemony as a lived sense of class that "saturates the whole process of living", there's a possibility that we might need to look beyond the prevailing vocabularies of interactional discourse analysis to more encompassing notions of subjectivity. ${ }^{8}$

I shall refer back to these issues at a number of points in my empirical analyses.

\section{Methodological preliminaries}

The data that I will draw on comes from a 28-month project focusing on multilingualism and heteroglossia among adolescents at school. ${ }^{9}$ Fieldwork lasted about a year, and datacollection involved interviews, participant observation, radio-microphone recordings of everyday interaction, and participant retrospection on extracts from the audio-recordings. My analysis focuses on four youngsters ( 2 male, 2 female) in a tutor group of about 30 fourteen year olds at a relatively disadvantaged comprehensive school in inner London. ${ }^{10}$

There are obviously many ways of thinking about class processes, and even within its relatively restricted focus on language and class identity, this paper is still very much

${ }^{8}$ See Gal [1991] 2001: 424; Coupland 2001c: 203 \& Holland et al 1998: 13-15 for broadly comparable reflections.

${ }^{9}$ Multilingualism and Heteroglossia In and Out of School (1997-99) funded by the Economic and Social Research Council (R00023 6602). Data from this project has been written up in Rampton 1999b, 2001b, 2002.

${ }^{10}$ Almost a third of the students at the school were classified as having special educational needs, a large number moved away before they completed their compulsory education, and the school did badly in the national league tables of pupil performance. Almost half of the pupils in the tutor group I studied received free school meals. At the same time, the teachers I interacted with struck me as left-of-centre, independentminded, and intellectually committed to trying to get to grips with the complex urban environment where they worked. 
only a part of work-in-progress. ${ }^{11}$ Even so, a number of potentially significant patterns have started to emerge. Quantitative sociolinguistic analysis has shown that there was a substantial proportion of vernacular London features in the routine speech of my four focal informants, and phonological style-shifting on the formal $\leftrightarrow$ informal axis appears to fit with conventional patterns of sociolinguistic stratification, getting 'posher' as the formality of the situation increases (Rampton 2001: 85-87). At the same time, I have not been able to find much evidence that these students had an assured or fluent command of any radical or resistant discourses of social class, and in terms of explicit discussion, expressed through the lexico-grammar, they seemed much more articulate about other kinds of social differentiation - as topics, ethnicity, gender and sexuality were all far more noticeable. ${ }^{12}$

Turning to stylisation itself, my analysis draws on 37 hours of audio-data which I recorded by giving the four informants radio-microphones to wear in the course of their ordinary school day, and it focuses on about 65 transcripts, which vary both in length and in the amount of exaggerated posh and Cockney that they contain. I have used a range of cues and resources to distinguish stylised performance from the routine variability, ${ }^{13}$ and

${ }^{11}$ To get a fuller picture of class as it affects these young people, ongoing analysis attends to: (i) their school's position and ethos just after a period of massive educational restructuring; (ii) the accounts of social class provided by teachers in lessons; (iii) the students' ethnic, occupational and linguistic backgrounds, and their general dispositions and trajectories within recreational and institutional space; (iv) their views of class, as articulated in interviews, in lessons and in peer discussion; (v) their routine linguistic performance (assessed with the tools of variationist dialectology); and (vi) their stylisations of posh and Cockney within situated activity. In this paper, I focus mainly on (vi), though I also refer briefly to (v) and (iv).

12 Teachers raised social class as an issue in history lessons and tutor periods, and I asked about it a bit in interviews, but it seldom seemed to resonate very much with these kids.

${ }^{13}$ Exaggerated performance - stylisation - was differentiated from routine variability in a number of ways.

The first and most obvious resource was my own intuition as a (relatively standard-accented) speaker who was brought up and living in the London area and who had spent quite a lot of time talking and listening to these youngsters. In listening through my recordings for the first time, it was this that I drew on when I first identified particular strips of talk as perhaps involving stylisation. Phonetic descriptions of Received Pronunciation and of London speech, particularly those provided by Wells 1982:Chs 4.1 and 4.2, provided essential back-up and meta-language for this, not only in ratifying particular utterances as being London rather than, say, Yorkshire, but also in helping to classify them as being particularly strong/broad versions of posh or Cockney.

These segmental phonetic clues provided a first point of entry into the analysis. But they were generally only one ingredient in an ensemble of semiotic features that constituted a stylised 'performance', and the co-presence of these other elements was another important indicator. Stylised performance was sometimes signalled and set off from the speech used both before and after by: An increased density in the co-occurrence of marked phonetic features, sometimes accompanied by marked grammar or lexis; quotative verbs 'say' or 'go', introducing reported speech; abrupt shifts in some combination of loudness, pitch level, voice quality or speed of delivery. In addition, stylised utterances were also often formulaic in their lexis and pragmatic function, as well as stereotypic in the characteristics of social personae which they portrayed (cf Bauman [1975] 2001: 171).

If the audience (or indeed the speaker) subsequently responded by laughing, repeating the utterance, by commenting on it, or by switching into a different kind of non-normal dialect or voice, this could be another clue. 
the first episodes to be discussed come from a set of interactions where young people's identities as pupils are at issue, where talk is addressed to school tasks, or where teachers are salient, either as interlocutors or topics (c. 20-25 episodes in all).

\section{Stylised 'posh' and institutional encounters}

Extract 1 is one of the most obviously oppositional instances of stylisation in my corpus, and it shows Ninnette and Joanne using ultra-posh accents in response to an indignity experienced in pupil-teacher interaction: ${ }^{14}$

(1) 'posh laughs'

Joanne, Ninnette and David (a boy), and perhaps a few others. They have been talking about the radio-microphone that Joanne's wearing, when Ninnette starts to talk about $\mathrm{Mr}$ Alcott, who they had been talking a couple of minutes earlier (Blex 71 44/160)

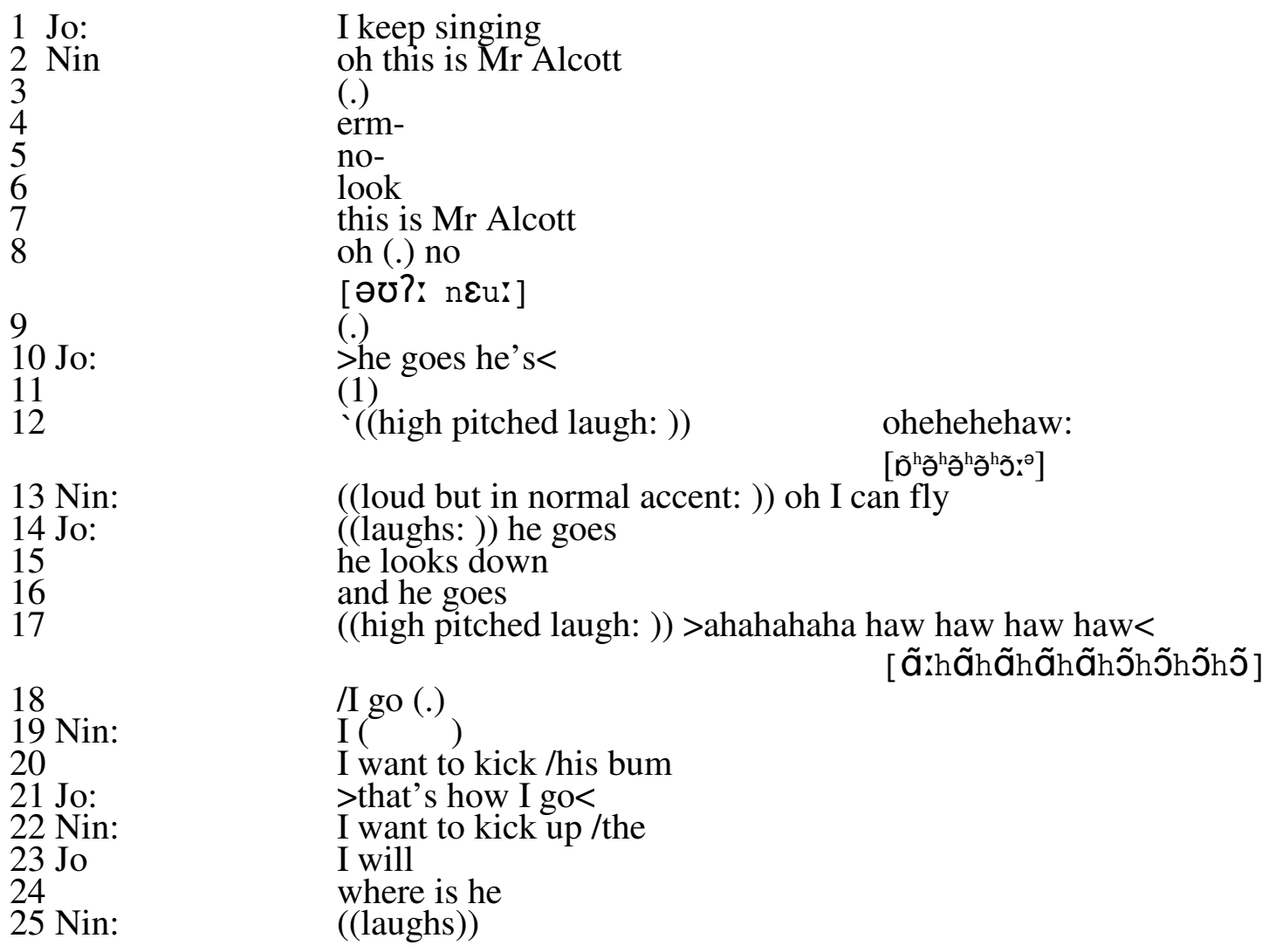

Finally, a significant number of 'candidate' instances recorded on radio-mic were replayed to the participants, and this also helped to clarify whether or not an utterance involved stylisation.

14 Joanne was of white Anglo descent, she received free school meals, and her dad was a selfemployed manual worker. Ninnette's ethnic background was black African Caribbean, and her mother worked in domestic service. 
At the start of the extract, Ninnette sets up an impersonation of Mr Alcott - 'oh this is Mr Alcott' (line 2) - and then focuses on some visual/physical aspect of the scene (line 6: 'look'). Without a visual record (and no playback commentary), we can't say either what physical actions or features she is performing, or exactly what attitude the 'oh no' in line 8 is intended to express - whether the 'oh no' signified fear, dread, boredom or distaste might well depend on Ninnette's facial demeanour in uttering it. But it is articulated in a posh accent - 'oh' is Received Pronunciation, and the 'no' is 'hyper-RP', with a fronted, half-open vowel at the onset of the diphthong 'now widely considered to be affected' (Wells 1982: 294). Joanne enters the spirit of this impersonation, and elaborates the scene with a couple of high-pitched, nasal, stereotypically very posh laughs, but before she's finished her cameo and had time to reenact her own response to Mr A (lines 18), Ninnette steps out of the Alcott guise to announce that she'd like to kick him (line 20), an idea which Joanne then offers to actualise (lines 23-24).

Ninnette's facial expression in uttering 'oh no' is not the only obscure element in these data, and it's hard to know exactly how 'oh I can fly' in line 13 and 'he looks down' in line 15 fit into the unfolding cameo. ${ }^{15}$ But from the audio-record, we can identify the encounter with Mr Alcott that provoked this exchange between the two girls, and it took place a couple of minutes earlier: ${ }^{16}$

(2) 'free food'

In the playground at breaktime, a couple of minutes before Extract 1(posh laughs). Mr Alcott is on duty, and Joanne, Ninnette and Linda go up to him to ask him about whether in their tutor group lesson immediately after break, they are going to continue the discussion of racism that had been initiated in the short registration period at the

15 'Oh I can fly' probably refers to R. Kelly’s “I believe I can fly”, which had just been released.

${ }^{16}$ In fact, they had encountered Mr Alcott several times that morning, first in their tutor-group period and then in a Humanities class. But there was nothing in either of these two sessions that resembled the direct exchange between Mr Alcott and the girls which had occurred in the playground shortly before Extract 1. Also, given the lapse of time since the last lesson contact (about an hour), as well as the intervening exchange, one would expect some extra contextualising work from Ninnette if she had an episode that occurred in the early part of the day in mind - for example, 'this is Mr Alcott in tutor'. 
start of the morning (a discussion which had been occasioned by a racist incident the previous day).

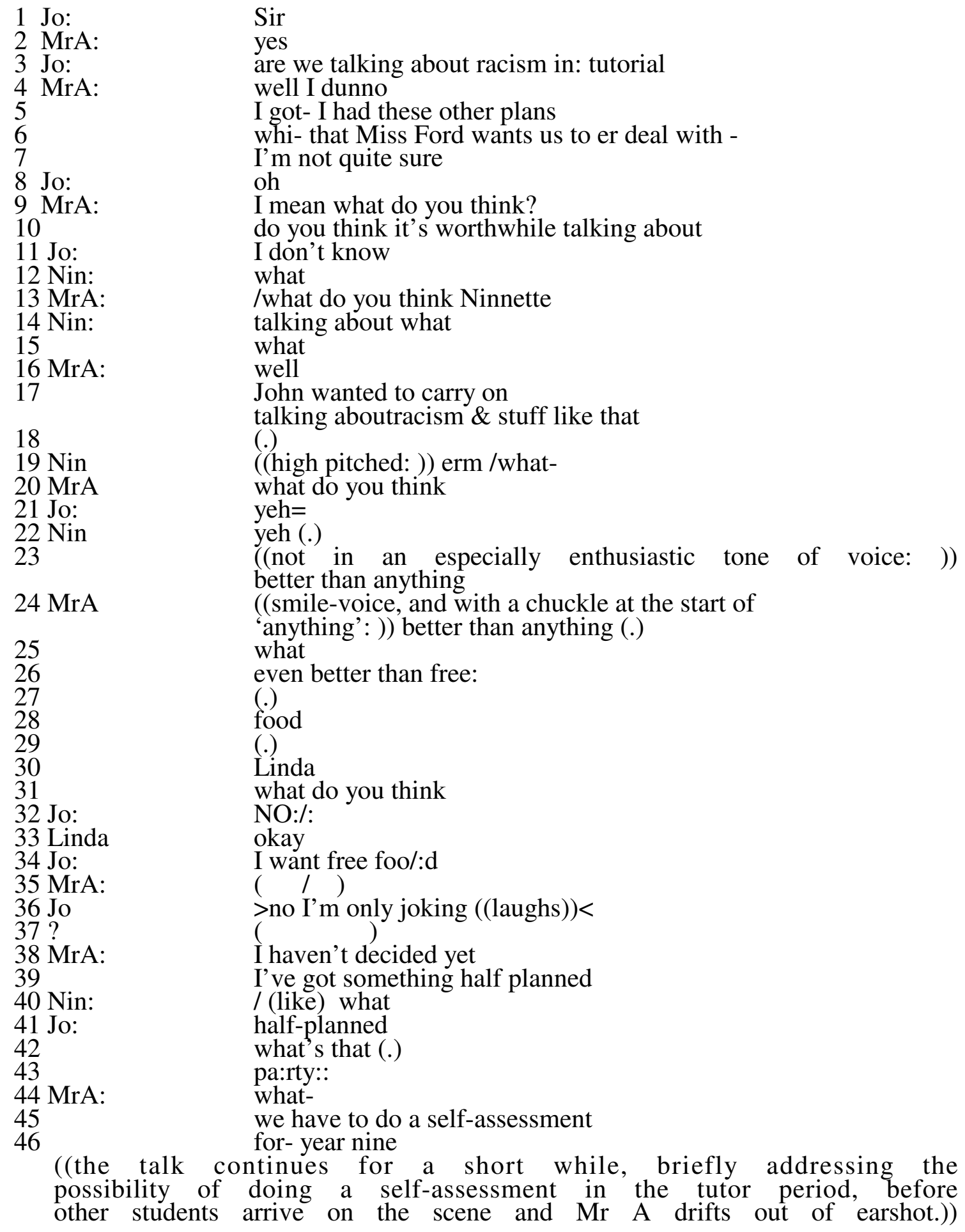


Nothing that Mr Alcott says bears any immediate resemblance to the posh 'oh no' or the extravagant 'haw haw' laughs that the Joanne and Ninnette subsequently use to impersonate him, and so if there was any versimilitude in their impersonation of him in Extract 1, it had more to do with physical action than with voice. Indeed, far from being haughty and dismissive, over the interaction as a whole, Mr Alcott solicited their views about what to do in the up-coming tutor-period, and adopted a generally open and consultative tone in telling them about the other possibilities he was thinking about. There was, however, one moment when he did re-key the interaction, and this occurred within the exchange directed to Ninnette in lines 20 to 29.

In line 23, it's impossible to say whether Ninnette's 'better than anything' actually meant 'better than any of the other possibilities on hand'. But in line 24, Mr Alcott first recycles it as an item requiring clarification - as a 'repairable' (Levinson 1983: 339-342) and then, rather than waiting or encouraging her to specify the scope of her comparison, he hyperbolically recasts the meaning of her words, presenting the possibility of her preferring a tutorial discussion of racism to free food: "What, even better than free food" (lines 25-28). Within the normative structure of conversational repair, in the event of Ninnette failing to clarify what she meant straightaway, the politest course of action open to Mr Alcott would have been to allow Ninnette herself to clarify what she meant once he had signalled his incomprehension (see Levinson 1983: 339-342). In fact, though, Mr Alcott not only preempts any self-repair by Ninnette, but also upgrades his turn into something that bears the hallmarks of a playful tease. The chuckle in Mr Alcott's voice in line 24 signals a humorous intention and lines 24 to 28 bear close resemblance to the teases described in Drew 1987 (see pp 231, 235), both in offering an extreme version of what Ninnette might mean, and in being closely modelled on the verbal material offered in the Ninnette's prior turn (lines $24=>23$ ). In addition, teasing turns "[s]omething which is normal, unremarkable, etc.,... into something abnormal" (Drew 1987: 244), and usually, the deviant attribute or identity being conjured has at least some potential 'real-world' relevance to the person being teased. Exactly what the relevance of 'food' is isn't clear: On the one hand, Ninnette was quite well-built and sometimes worried about her size, while on the other, she also liked to talk about food - it is one of the most recurrent topics in the recordings of her and as her form tutor, Mr Alcott might well know of this. ${ }^{17}$ But whichever way it is (and was) interpreted, there is a sense in which Mr Alcott's rather facetious exaggeration actually cuts 'close to the bone' (Drew 1987: 246).

Mr A's "what, even better than free food" might be intended as a playful tease, but it doesn't appear to go down very well with Ninnette. In Drew's data,

" $[\mathrm{t}]$ he overwhelming pattern is... that recipients [the persons being teased] treat something about the tease, despite its humour, as requiring a serious response: Even when they plainly exhibit their understanding that the teasing remark is not meant to be taken seriously... recipients still almost always PUT THE RECORD STRAIGHT” (1987: 230. Original emphasis)

But in the episode here, Ninnette remains silent. In line 29, there is a micro-pause at the end of the tease where she could have intervened, but noone relieves Mr Alcott of the

${ }^{17}$ I am grateful to Sue Gal for pointing out this ambivalence. 
speakership, and instead he 'down-keys' by returning to the more serious business of soliciting the students' views on what to do in the tutor period by redirecting the attention to Linda. If Ninnette had responded to the extreme version offered by Mr Alcott, her rejoinder would have helped to constitute the interaction as a bit of playful pupil-teacher banter, but from her silence it looks as though Mr A's remark has been experienced as a put-down. Joanne's subsequent intervention temporarily sustains a playful key, but itself evidently runs into some difficulty - "no, I'm only joking" (line 36). ${ }^{18}$

Against this background of recent experience, the girls' conversation in Extract 1 now looks like symbolic retaliation, fictively paying Mr Alcott back for the sense of humiliation created by "even better than free food". We ourselves might find it hard to detect any imperious condescension in Mr Alcott's demeanour in Extract 2 - he was talking to the girls in an open and consultative manner, and it seems more likely that his teasing remark was intended in a spirit of familiarity and friendliness (Drew 1987: 220). But within the stylised performance she initiates in line 2 of Extract 1, Ninnette's switch to a high-class accent suggests that she interprets the encounter as an asymetrical one, and the fact that Joanne then selects laughter for her own performance of ultra-poshness in line 12 shows her own sensitivity to what it was in the interaction with Mr Alcott that caused Ninnette offence - the moment of (purported) playfulness. In actual fact, Mr Alcott's only mistake may have been to assume a reciprocity with the girls that they didn't themselves share, and immediately after the tease in line 26, Ninnette may have been prevented from setting the record straight more by her own sense of the difficulties involved in answering a teacher back than any real threat from Mr Alcott. Now, though, Mr Alcott has now been demonised as a mocking snob in the kind of 'backstage' replay that James Scott attributes to the 'hidden transcript', where "in the relative safety of their quarters [, subordinates] can speak the words of anger, revenge, self-assertion that they must normally choke back when in the presence of the masters and the mistresses" (1990: 18). ${ }^{19}$ Admittedly, there's nothing in Ninnette's awkward moment in Extract 2 to compare with the situations of dire

${ }^{18}$ In lines $32 \& 34$, Joanne makes an attempt to respond in the bantering frame initiated in $\mathrm{Mr}$ Alcott's tease, and she tries to hoist him on his own petard, claiming that actually, she would prefer free food to anything else. In doing so, she keeps the key of the encounter light, ratifying Mr Alcott's 'free food' remark as a primarily playful one, and she also rallies to her friend in a spirited and oppositional endorsement of the values that Mr Alcott's tease attributed to Ninnette. But from her "no, I'm only joking", it looks as though she has doubts about sustaining this. It's hard to know what the source of her doubts is, but without any signs that Ninnette is willing to play along with the non-normal identity that Mr Alcott jokingly attributed to her, it might look as though Joanne was colluding in the teasing of Ninnette if she kept it going. Joanne does return to a playful key when she proposes that Mr Alcott's incipient plans might involve a party, and perhaps she does so to attest that there really is more to her humour and her interest in pleasure pursuits than just an opportunity to join in the teasing of Ninnette. But there are no audible signs that Ninnette is willing to play along.

${ }^{19}$ In fact, remembering Ninnette's failure to set the record straight after Mr Alcott's tease, it looks as Extracts $1 \& 2$ constitute a good instance of the processes generating the 'hidden transcript': "It is this systematic frustration of reciprocal action in relations of domination which, I believe, helps us to understand much of the content of the hidden transcript. At its most elementary level, the hidden transcript represents an acting out in fantasy - and occasionally in secretive practice - of the anger and reciprocal aggression denied by the presence of domination. Without the sanction imposed by power relations, subordinates would be tempted to return a blow with a blow, an insult with an insult, a whipping with a whipping, a humiliation with a humiliation." (Scott 1990: 37-38. Original emphasis.) 
oppression and humiliation that Scott describes, and indeed $\mathrm{Mr}$ Alcott's generally consultative stance in the episode points to an egalitarian spirit that was actually quite widespread among the staff. Even so, we can see in Extract 1 that despite such circumstances, class consciousness still survives, affording a shared and readily accessed imagery that both girls can draw on in their fantasy of vengeance. In pupil-teacher relations at least, class remains an emically resonant identity.

Since schooling involves rewards, penalties, reputations and identities that can be consequential for students' future position within systems of production, distribution and consumption, and since it almost inevitably involves asymetries of institutional power, pupil-teacher interaction is maybe a site where one would expect to find everyday displays of class consciousness. But stylised posh and Cockney accents were also used in recreational interactions where there was no obvious conflict over the status of different groups or individuals. Was social class necessarily still relevant? After all, these youngsters lived in London, encountered lots of different kinds of Londoner every day, and so it's logically quite conceivable that specific dialect performances could be intended to conjure the image of particular people as individuals, rather than as emblems of any more general social type or group. This is a possibility we need to consider in the next three extracts, which come from a set of about 15 recreational episodes where no-one sought to exercise institutional control, but where something more than just the sound properties of posh or Cockney seems to be in focus. Of these data we should ask:

a) is social class actually relevant to our understanding of these episodes, and then if it is,

b) where do we locate it, in terms of the issues raised in Section 1? Is class a strategic interactional identity projection, or can we see it somehow structuring the consciousness at work in the discourse?

\section{Stylised posh and Cockney in peer-centred interaction}

The next two episodes are quite closely connected thematically, and again involve Joanne and Ninnette in the stylisation of posh.

In Extract 3 immediately below, Ninnette has just been given the radio-microphone (by me) outside in the playground, and conscious that they are being tape-recorded, she and Joanne are playing with risqué sexual topics, incriminating each other, and pretending to censor key words by inserting 'beep' into their utterances, a device used in broadcasting to eliminate words deemed improper. Joanne has just said

as I know from previous experience, Ninnette is very strong (.) she likes to catch boys' beep

Ninnette returns:

(3) 'rude thing'

(blex 59 33:77)

$1 \mathrm{~N}: \quad$ and YOU:

2 (.) 


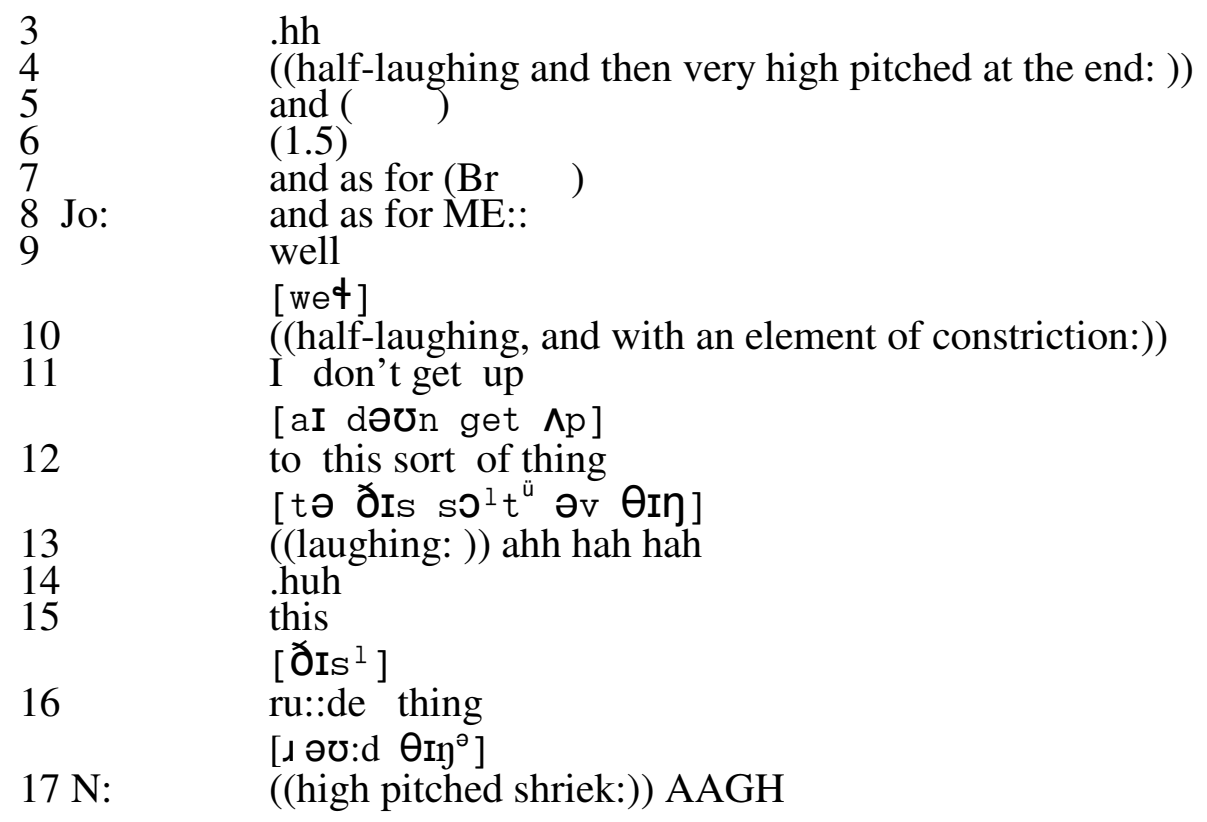

Within this playful sequence of incrimination and denial, Joanne's claims to proper conduct in lines 9-12 and 15 are 'carefully' enunciated with standard rather than Cockney consonantal variants. ${ }^{20}$ This style can be designated 'literate speech', and it follows in a tradition that Mugglestone dates back to Dr Johnson's dictum: "For pronunciation the best rule is, to consider those as the most elegant speakers who deviate least from the written words" (Mugglestone 1995: 208). And in this instance, it suggests a rather commonplace association between standard speech features and restrained/refined sexual conduct, counterposed to the vulgarity that Joanne jokingly attributes to her friend. But exploitation of this social imagery was not always so straightforward, and Joanne invoked it in less blatant, more piquant ways elsewhere:

(4) 'Ricky \& Ninnette'

A week later, Joanne, Ninnette and others are in the playground during break (blex 78: 49/260). Ninnette and Joanne have been talking about a party Ninnette says she's arranging, joking about booze, sex and the boys they could invite. Ninnette then notices Ricky, a boy that she fancies but doesn't go out with:

$\begin{array}{lll}1 & \text { N: } & \text { oh oh oh } \\ 2 & & \text { my boyfriend's here } \\ 3 & & (2) \text { ?short kissing noise: )) mwa } \\ 4 & \text { Jo: } & (3) \\ 5 & & \text { ((audibly moving away from Joanne and the mic: )) }\end{array}$

${ }^{20}$ Joanne selects standard rather than Cockney variants for

- the L in 'well' in line 9, which is velarised rather than vocalic (Wells 1982: 313-317)

- the Ts in 'get' and 'sort' in lines 11 and 12, which are alveolar rather than glottal (ibid: 324-325)

- the THs in 'this' and 'thing' in lines 12, 15 and 16, which are alveolar rather than labio-dental (ibid: 328329) 


$\begin{array}{ll}7 & \\ 8 & \text { Jo: } \\ & \\ 9 & \\ 10 & \\ 11 & \\ 12 & \\ & \\ 13 & \\ 14 & \text { Boy: } \\ 15 & \text { N: } \\ 16 & \text { Jo: } \\ 17 & \\ 18 & \\ 19 & \text { N: } \\ 20 & \text { Jo: } \\ 21 & \\ 22 & \\ 23 & \\ 24 & \end{array}$

my little scooby do thing

(2)

((posh, at a higher than normal pitch level: ))

oh you are: here

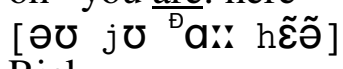

Ricky

(.)

Ricky

((quietly, with half-laugh at the end:)) Ninnette's here

(1)

((a little way away: )) ( coming to your party)

$\mathrm{N}:$

((a little way away: )) (

hh $($ )

((loudly, in a vernacular accent: )) Ninnette

I bet you're gonna invite him

$\mathrm{N}:$

(

no

you're too shy:

(1)

cos if he asked you out

((high-pitched: )) OOH:: NO::

In this episode, there is quite a lot of moving around in a relatively crowded outdoor space, and it is hard to hear or follow everything that's going on in it. But in line 6, Ninnette moves away from Joanne, leaving her silent for about 2 seconds. From the lack of an audible response to her utterances in lines 8-9 and 11-12, from the inaudibility of the talk later on in lines 14 and 15, and from the increased loudness with which she uses Ninnette's name to regain her attention in line 17 , it sounds as though in line 7 , Joanne temporarily becomes a solo bystander, somewhat at the edge of whatever's going on. Then, left to the side like this, in lines 8-12, she performs what sounds like a small piece of dramatic commentary on the scene she's observing, beginning with 'oh you are here', the change-ofstate token ('oh') and the stress on 'are' both suggesting that up until now, she hadn't taken Ninnette's earlier claim seriously (line 8). She also appears to address Ricky himself (lines $9 \& 11$ ), though once again, the circumstantial details mentioned above lay it open to question whether or not she actually expects to be heard.

It seems even more likely that she's engaged in self-talk in her next utterance in line 12, where she also formulates the sentence as if it was addressed to Ricky, but actually drops her voice and speaks more quietly - "Ricky, Ninnette's here". Even though they're co-present, Ricky evidently isn't talking to Ninnette, and in this utterance, Joanne pretends to draw his attention to her. There are good reasons, though, why she should keep this relatively quiet.

Joanne knows that Ninnette fancies Ricky, but she has no reason to suppose that Ricky reciprocates. Because of this, it would be very presumptuous if she really did single Ninnette out for Ricky' attention. It would betray Ninnette's confidence, make her interest in Ricky obvious to him, and also force him to a declaration in the order of either "Hi Ninnette!" or "So? Fuck off!' - her friend might not feel quite ready for that, as Joanne herself subsequently acknowledges in lines 18-24. On the other hand, as is often the case among adolescents (e.g. Foley 1990: 33,70,95; Rampton 1995: 187-189), such disclosures were the focus of a great deal of peer group activity, and even only in anticipation, they 
seemed replete with risk and promise for one or both of the named parties, and an endless source of entertainment for their friends. It is this rich vein of excitement, ambivalence and potential embarrassment that Joanne is playing with in her apostrophe to Ricky, and she animates it with a switch to much posher than normal speech.

In line 8, Joanne's 'here' sounds like 'hair' ([hE己]). The first part of the centring dipthong is much more open than is typical either in 'ordinary' RP [Iə] or in Cockney [iə], and to me anyway, this makes it sound very upper class. Her second 'here' in line 12 contains an open second element - i[ ] ] that Wells associates with "the duchess, officer and don stereotypes" (1982: 281), and neither involves any Cockney H-dropping. Though the need for pseudonyms prevents me giving details, Jo's pronunciation of Ninnette's name in line 12 is also noticeably standard, containing 'literate' elements that are then dropped when she repeats it a moment later in her normal accent in 17, and there's also no Cockney glottalisation of the intervocalic / $\mathrm{k} /$ in Ricky in lines 9 and 11 (Wells 1982: 324). It would be foolish to try to be too specific about the aesthetic effect that these phonetic selections produce within her performance overall, but assuming that posh is associated with politeness, putting-your-best-foot-forward and/or sexual restraint, it introduces a note of formal propriety into Joanne's mock mediation, and when this is laid over the subterranean abundance of sexual, amatory and/or embarrassing consequences than the encounter might unleash, it gels in something like an oxymoron, a knowing encapsulation of both inhibition and desire.

Before starting to pull the patterning in these extracts together, it is worth looking at an episode where posh and Cockney are juxtaposed, set within a shift of footing where there is quite a sharp contrast in the cultural values and communicative forms that they're each associated with:

(5) 'buggaye'

During the tutor period while $\mathrm{Mr}$ Alcott is talking to the class about an racist incident the previous day, Joanne (wearing the radio-mic) has been telling Ninnette a bit about her parents and grandparents, and has just talking about her mum's difficult pregnancy (blex 68 42:244):

((quietly: )) she could have lost me ((light laugh))

(3)

((with a hint of tearfulness in her voice: ))

$\mathrm{n}$ you'd all be sitting here today without me ((la/ughs))

$$
\text { [sIt?In hIO] }
$$

5 Tannoy: ((eleven pips, followed by the din of chairs moving))

6 Jo:

((louder, and in literate speech: ))

but you wouldn't care

[bt jə,w wdünt $\left.{ }^{u ̈} k \varepsilon \partial\right]$

cos you $\mid$ wouldn't $\mid$ know ((laughs))

[kəz jə wUd $\left.\mathrm{du}^{\mathrm{IJ}} \mathrm{n} \tilde{\mathrm{x}} \mathrm{u}\right]$

8 ?N:

( )

$9 \mathrm{Jo}$

10

nothing I'm just jok- )

11

I'm being st-

((high-pitched) $) \wedge_{\text {oooh:: }}$

[uis ] 
$\Lambda_{\text {Ninne::tte }}$ you've got enough with you today [ju gDt en $\wedge f \mathrm{wI}^{\Theta}$ ju: tədẽ̃̃] and then you go and chee::k me::

At the start of the extract, Joanne finishes her story with quite a momentous conclusion: She could have died before birth (line 2). But there's no audible response (line 3) (understandably, perhaps, in view of the fact that the teacher's talking to the whole class and Joanne and Ninnette are having to chat sotto voce anyway). Joanne doesn't leave it at that, though, and with a suggestion of mock tearfulness in her voice, she draws out the immediate consequences of her mother's loss - "you'd all be sitting here today without me" (line 4). Before there's any uptake, the Tannoy interrupts, announcing the end of the lesson with a series of loud pips, and when pips have finished, Joanne resumes with a dramatic change of footing. The picture of a school class saddened by her absence is logically contradictory - 'but you wouldn't care cos you wouldn't know' (lines 6 and 7) - and in the deflation of such sentimentality, Joanne combines 'literate speech' with epigrammatic style. There is no elision (or glottalisation) of the alveolar consonants in either of the two "wouldn't's", and instead, the plosives [d] and [t] are aspirated in three of the four occasions where they occur. At the same time, the sentence breaks into two lines characterised by rhythmic, grammatical and lexical parallelism

$$
\begin{array}{lllll}
\text { bt } & \text { you } & \underline{\text { would }} & \text { n't } & \underline{\text { care }} \\
\text { cz } & \text { you } & \underline{\text { would }} & \text { n't } & \underline{\text { know }}
\end{array}
$$

and the formulation of a sardonic analytic point in this succinct poetic structure warrants comparison with the classical epigram: "A short, polished poem ending with some graceful, ingenious, pointed, weighty, witty or satirical turn of thought; more personal and specific than a proverb" (Shipley (ed.) 1970: 103).

Ninnette's reaction to this isn't audible (line 8), but from what follows, it must have involved some kind of challenge (something such as 'what are you up to?'). Joanne begins to formulate a retraction, minimising what she's just been saying and explaining that it wasn't serious in lines 9 \& 10 ("nothing, I'm just jok- ((=> joking)), I'm being st- $((=>$ stupid?))") but before she's finished, she interrupts herself with an emphatic change-ofstate token and redirects the focus from herself to her friend, using a stretched rise-fall in

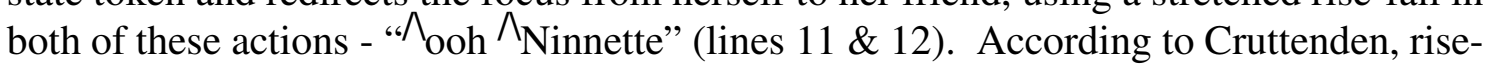
fall tones tends to express attitudinal stances of either 'being impressed' or 'being

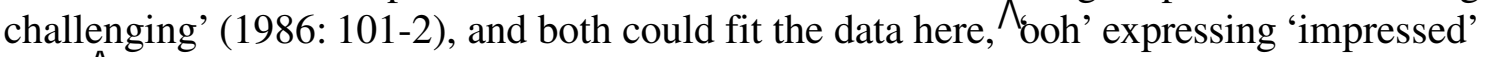
and 'NNinnette' articulating 'challenge'. These are then blended in lines 13 and 14 in an indignant reprimand, in which she accuses Ninnette of already being at the limits of tolerable conduct ("you've got enough with you today" line 13), and of then exceeding these limits with impertinence ('and then you go and cheek me'). After that, the sequence closes with a damning summary of Ninnette's character: 'You little buggaye aye aye aye'. 
Of course Joanne isn't being serious here - you can only be cheeky to someone who is older or in a superior position, and since Joanne and Ninnette are actually peers of the same age, it would be a fatuous accusation if she really meant it. Instead, in claiming to be the recipient of Ninnette's cheek, Joanne is playing a part, and she articulates this in the London vernacular, using L vocalisation and T glottaling in Ninnette's name and in 'little' in line 16, as well as (what sounds to me like) a non-standard idiom in line 13 ("you've got enough with you today").

Overall, Joanne's performance in this extract constructs a quite a sharp contrast between the footings associated with standard and vernacular speech. With the shift to careful 'literate' speech, she uses logic to undermine sentiment, and symetrical patterns of rhythm and grammar provide her propositional argument with elegant poetic structuring. In contrast, when she pretends to intensify the emotion in her speech - when she abandons her apology, cancelling the effort to restore equanimity to her relationship with Ninnette, and issues an indignant reprimand - her speech becomes markedly Cockney, and the relationship between sound and semantic meaning loses its balance. As a non-lexical response cry, the 'ooh' that Joanne uses to initiate her reprimand makes a "show of [being a] "natural emotional expression"" (Goffman 1981: 108), and in cutting mid-word into the apology that immediately preceded it, it makes the reprimand look like a spontaneous outburst. And then at the end, sound disrupts lexis once again when a word that initially looks like it's maybe going to be 'bugger' is carried off half-way through into a repetitive non-word sequence of 'aye aye aye aye'.

At this point, it is worth turning to consider the four episodes together, also referring as necessary to the larger subsets of posh and Cockney stylisations of which they form a part.

\section{Some commonalities}

In the episodes we have looked at, we have seen a broad London accent featuring in the performance of passionate indignation (Extract 5), while posh has been associated with being gay (Extract 1, lines $28 \& 29$ ), with sexual restraint/inhibition (Extracts $3 \& 4$ ), and with elegant wit (Extract 4). Elsewhere in the data on socially symetrical interactions, Cockney collocates with, for example, territorial assertiveness (' gid out', 'gid out of London') and with bodily relaxation/freedom ('led it out', where 'it' refers to belching). Posh on the other hand is used to express mock trepidation at a threat that's judged unmanly ('ohno, Mansur, don't...'), and is linked to inanity in sport ('oh helloo', addressed to an arriving football by someone who says their new glasses stop them seeing it properly). Reframing this, we can say that a relatively standard accent is used to articulate an incompetent or uneasy relationship with both the body and with feelings and emotions (e.g. Extracts $3 \& 4$ ), that the words selected express an apparent regard for social decorum (e.g. Joanne's feigned mediation between Ninnette and Ricky in Extract 4), and that there is an association with literate cultivation rather than oral spontaneity, both in the use of 'spelling' pronunciation (Extract 3 ) and in the approximation to a classical genre (the epigram in Extract 5). A broad London accent, in contrast, is associated with bodily activity, with the expression of feeling unconstrained by social manners (e.g. Extract 5), with profane 
language that emphasises sexual activity ('eff off'), and with a disruption of conventional (written) word structure ('buggaye'; elsewhere 'gid out' becomes 'gidyoo').

A pattern emerges, then, in which vigour, passion and bodily laxity appear to be associated with Cockney, while physical weakness, distance, constraint and sexual inhibition are linked to posh. In fact, at a more abstract level, this can be easily accommodated within a more general set of contrasts between mind and body, reason and emotion, high and low. According to Bourdieu, the notion of 'popular speech' is itself

"one of the products of the application of dualistic taxonomies which structure the social world according to the categories of high and low..., refined and coarse... distinguished and vulgar, rare and common, well-mannered and sloppy" (1991: 93)

and in Phil Cohen's analysis (1988), the emergence of 'class racism' from the $17^{\text {th }}$ to the $19^{\text {th }}$ centuries in England was built around a contrast between on the one hand, elevated reason and 'bourgeois virtues of industriousness and thrift", and on the other, sexual promiscuity and "the body..., the heart of unreason, the site of 'base pleasures' and vulgar instincts as against the higher and more refined faculties" (1988: 66, 67). This dualistic idiom, argues Cohen, was generated "from within certain strategic discourses in British class society, [and] from the very outset [it was] applied across a range of sites of domination, both to the indigenous lower orders and ethnic minority settlers as well as to colonial populations overseas" (1988: 63). Mugglestone's historical account of selfimproving efforts to 'talk proper' documents some of the linguistic consequences of these dualisms; Stallybrass and White propose that this 'high-low' dichotomy is fundamental to bourgeois subjectivity (1996: 202); and indeed, within quantitative sociolinguistics, variations on this idiom have been repeatedly reported in matched guise studies of speech evaluation (Giles and Powesland 1975: 68; Trudgill 1983: 211).

So across the range of stylised performances of posh and Cockney, each with their own contingent and emergent properties (Hanks 1996: 257-258), it looks as though these youngsters were reproducing a 'cultural semantic' (Stallybrass \& White) that is very wellestablished both in Britain and in class-stratified western societies more generally. Admittedly, as Cohen notes, the dichotomies of high-low, mind-body, reason-emotion also play a major part in other kinds of social stratification, most notably perhaps in gender and ethnic relations (see Cohen 1988), and the relationship between stylised posh, Cockney and other category memberships still awaits detailed analysis. ${ }^{21}$ But overall, if we draw the different sources of evidence together, it looks as though the cultural and linguistic legacy of British class relations could be significant in these data. Cultural analysts associate class with the dualities of mind-body, reason-emotion etc; historical and variationist sociolinguists associate class with posh and Cockney; and my informants introduced posh and Cockney into stylised performances in which they engaged with these dualities. Indeed, if there were any need for it, these data might themselves be taken as corroboration of the cultural analysts' claims about the class provenance of such dualism.

\footnotetext{
${ }^{21}$ As far as gender is concerned in the data we are considering, masculinity was explicitly associated with bodily power and freedom in a couple of episodes, and there may be resonances of the 'scolding mother' in the ticking-off that Joanne gives Ninnette in Extract 5.
} 
There are quite good grounds for saying, then, that class is relevant to these data, if only as the historical matrix giving shape to the cultural-linguistic complex that we've identified so far. But do these data help us to engage with the questions about class identity raised in Section 1? Is class best conceptualised as an interactional identity projection, or is there evidence here of class hegemony as a subjective condition?

Up to a point, this question might best be answered by an extended philosophical discussion that addressed the relationships between action, intention and subjectivity, that interrogated more closely my attribution of different interpretive idioms to interaction analysis and cultural studies, and that sought a coherent theoretical reconciliation. Williams' notions of 'hegemony' and 'structures of feeling' usefully focus attention on the relatively enduring sensibility of a given individual, group or artistic work, directing us beyond the momentary interactional impacts often prioritised in pragmatics, but in fact if we allowed this rather bald distinction to entirely dictate the terms of our engagement with the data, we could easily lose sight of the hugely complex interrelationships of agency and structure, of social relations, physical conduct, memory, emotion and the material environment (Williams 1977; Moerman 1988: 63-67; Hanks 1996; Billig 1999). However, although conscious of these risks, I would like to remain focused on my dataset, using one more episode to convey the resonance of class among my informants.

Of itself, the fact that these youngsters were playing on culturally rooted dualities of high-\&-low, mind-\&-body, reason- \&-emotion, does little to question theoretical models that presuppose a separation between symbols and the controlling subject who deploys them, or that see speech as involving the flexible strategic selection of social images from a mental repertoire of stereotypes, a stock of resources possessed by each speaker (e.g. Le Page \& Tabouret-Keller 1985: 181-186; Lippi-Green 1997: 30,63; Hudson 1996: 237-243; Rampton 1999a). All it illuminates, one could say, is something of the ideological structuring of the multi-dimensional socio-symbolic space that speakers allude to in their linguistic acts of identity, and so far anyway, the analysis hasn't really suggested any ways in which one might speak of subjectivity and feeling being structured by the processes of symbolic differentiation associated with social class, of the dualities of mind-body, reasonemotion, high-low playing a constitutive role in 'the fibres of the self' (Williams 1977: 212). We can start to close this gap, however, if we now turn to posh, Cockney and the grotesque.

\section{Posh and Cockney in the grotesque}

Here are Ninnette and Joanne in the playground once again:

(6) 'funny eyes'

Ninnette (wearing the radio-mic), Joanne and Linda are outside in the playground, and they're started to talk about their faces. (blex 62: 36:260)

$\begin{array}{lll}1 & \mathrm{~N}: & \text { Linda's face gets hurt more easily than mine } \\ 2 & & (.) \\ 3 & \text { Jo: } & \text { because yours in looser } \\ 4 & \mathrm{~N}: & \text { no } \\ 5 & & (.)\end{array}$


because she::

(.)

feels pain more than I do

(.)

Jo:

no

cos yours is looser

$\mathrm{N}$ :

((loud brief laugh)

(.)

loo:: $\quad((=$ 'look' $))$

((?Does something funny with her eyes for the first time))

16 Jo:

((laughs: )) hah hah /haah

$18 \mathrm{~N}$ :

it's a lot more $($ / $)$

loo(k) $\operatorname{loo}(\mathrm{k}) \operatorname{loo}(\mathrm{k})$

19

[lण? lण? 10?]

look loo(k)

20 Jo:

[lok 10?]

$21 \quad \mathrm{~N}$ :

Linda's skin's str/aighter

loo $(\mathrm{k})$

[10?]

22 Jo:

(2) ((Second performance of 'funny eyes'))

what're you loo- hhh ((:starts short breathy laugh))

(.)

$>$ (look a' 'er)< eyes

watch her eyes again

(2.5)

((Third peformance of 'funny eyes', accompanied by quieter speech:)) and whaT

$(($ Suddenly breaks into laughter for 2.5$))=$

$=$ loo: $\mathrm{k}$

[10?]

1- 1-

$/ \mathrm{loo}(\mathrm{k}) \operatorname{loo}(\mathrm{k})=$

[lण? lण?]

cow's eyes

=watch is

[wDt _ Is ]

$\left(4^{\text {th }}\right.$ performance of 'funny eyes', with quieter speech: ))

whaT

[wDt ${ }^{\mathrm{h}}$ ]

are you looKing aT

38 Jo:

[a: ju lokIn æt $^{\text {sh }}$ ]

((slowly, and quite quiet: )) your fu/nny:

39 Linda:

$41 \quad \mathrm{~N}$ : hea(d)

exaggerated

((layghing: )) loo(k) loo(k) hah hah hah

( $\left(5^{\text {th }}\right.$ performance, with speech that end with

lip-rounding: ))

WHAT hare you looking at

43 Linda:

[wDt ha: ju: lokin æe?]

(.)

45

lookin' at your funny eyes

(.) 


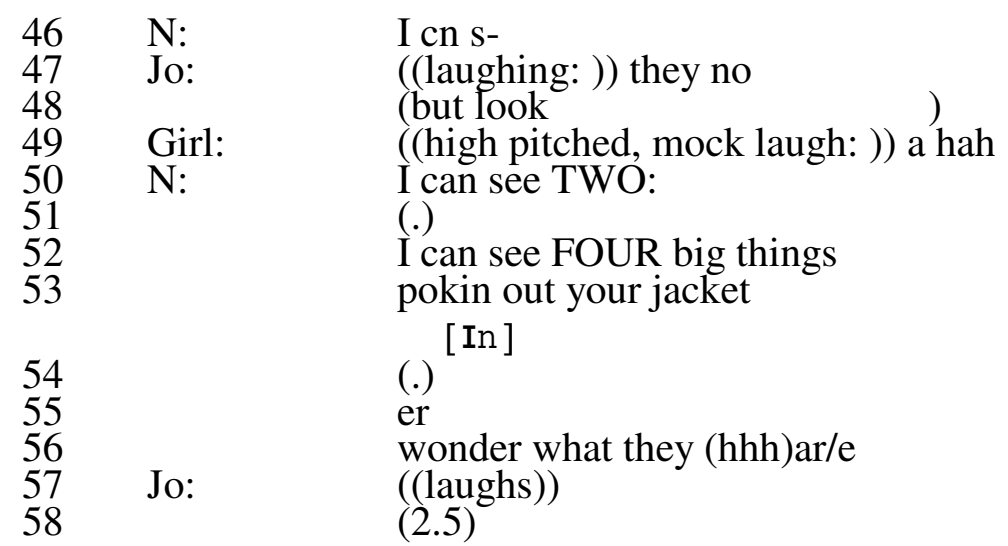

The extract begins with a short dispute between Ninnette and Joanne about the reason why Linda's face is more sensitive to pain than Ninnette's (lines 1-11). The argument hasn't developed very far when Ninnette laughs abruptly after Joanne's second reference to her 'loose' face and tells them all to 'look'. There's no visual record, but it's clear from the dialogue that follows that she's asking them to attend to her face, and that the spectacle they're to attend to involves her doing something funny with her eyes:

line 24: Joanne:

line 31: Linda:

line 40: Ninnette:

41: Linda: watch her eyes again

cows' eyes

what hare you looking at

lookin' at your funny eyes

From the stretched vowel of 'loo(k)' in line 14 and the laugh that follows immediately after (line 16), it sounds as though she pulls the face there and then, but Joanne doesn't notice, carrying on instead with her discussion of Linda's face (lines 17 and 20). Ninnette evidently decides that it's worth another performance, and so she now intensifies her efforts to get their attention, asking them to 'look' six times in quick succession (lines 18, 19, 21). In line 22 , she evidently judges that the audience is sufficiently settled, and performs the eyes act a second time. Joanne apparently tunes in a little late, but laughs when she catches on and suggests they see it again (lines 23-26). After an attentive pause (line 25), Ninnette starts her third performance, this time providing a verbal accompaniment (line 28), but she cracks up in laughter very soon after the start (line 29) and has to reassemble the audience (and recompose herself) (lines 30, 31, 32, 34). During the fourth and fifth performances in lines 36-37 and 42, the verbal accompaniment is fully articulated in the sentence 'what are you looking at', and it turns out that this involves a hybrid mixture of both posh and Cockney. ${ }^{22}$ This is combined with a stilted, effortful style of delivery, and together they

${ }^{22}$ The standard, careful and 'literate' speech features include:

- aspirated and also sometimes affricated Ts (in 'whaT' in lines 28, 36, 42 and in 'aT' in line 37);

- non-contraction of the auxiliary 'ARE' (lines 37 and 42);

- 'AND' realised with a non-schwa vowel and non-elided alveolar consonants (line 28)

- velar plosives in 'looKing', instead of the glottals used in the build-up (compare lines 37 and 42 with 18 , $19,21,32)$

- velar nasal realisations of 'lookING' in lines 37 and 42 (in contrast to the alveolar in 'pokIN' in line 53) 
bring hyper-correct, 'adoptive RP' to mind, what Wells calls the "the variety of RP spoken by adults who did not speak RP as children' (1982: 283). ${ }^{23}$

Certainly there are social types and real social groups who do use 'adoptive RP', but real groups and individuals aren't the focus of the girls' attention in this episode, they're not engaged in poking fun at particular people, and I personally can't think of any real or fictional precedent that warrants an association between (a) upward-aspiring-people-withlimited-linguistic-capital (the variationists' hyper-correcting Lower Middle Class) and (b) 'funny (cows) eyes'. Instead, it looks as though Ninnette is engaged in some kind of grotesque, and we can get more purchase on this, and move closer to cultural analysts' concern with subjectivity, if we refer in more detail to the work of Stallybrass \& White (1996).

Like other cultural analysts, Stallybrass and White argue that the differentiation of social groups on a hierarchy of high and low is a central cultural process in class societies, and that this has a profound impact on the way in which individuals make sense of the world. But very much influenced by Bakhtin (1968), they go on to propose that in the course of defining outgroups and marking the boundaries between 'us' and 'them', social groups develop a history with the Other and internalise an imagery that becomes dangerously unstable in the group's 'political unconscious', a mixture not just of fear and disgust but also of fascination and desire (1996: 194). One of the most powerful cultural expressions of this group process, they claim, can be found in the grotesque, and in one of its forms, the grotesque involves hybridization and inmixing, transgressing the boundaries that separate high from low. I think it is this that we are seeing in Extract $6^{24}$ Ninnette is performing peculiar physiognomical contortions, which she evidently feels highly compelling ("look look look look look look look look look" - lines 18-32), and to accompany them, she draws on a speech style which is widely recognised as a(n often comically anomalous) mixture of Cockney and posh. As a discursive and historical construction, says Skeggs, class includes "elements of fantasy and projection" (1997: 5), and, argues Ortner, "each class contains the other(s) within itself, though in distorted and ambivalent forms" (1991: 172). Fantasy, distortion, ambivalence and class are all evident in Ninnette's performance, and if we are willing to accept the orientation offered by Stallybrass \& White, then these data encourage us to locate posh and Cockney in these

At the same time, in the climactic fifth time round in line 42 ,

- a hyper-correct $\mathrm{H}$ is inserted into the auxiliary 'are', producing non-standard [ha: ], and

- $\quad$ in the effortful, lip-rounded final 'AT', there is a vernacular glottal rather than a standard alveolar stop. (With regard to the H-insertion, it's perhaps worth noting that Ninnette's family had roots in the Francophone Caribbean, and so there are no prima facie grounds for assuming that it derives from an English lexicalised creole, thereby indexing a Caribbean identity).

${ }^{23}$ Wells notes that "one crucial characteristic of most speakers of adoptive RP is their lack of control of the informal and allegro characteristics of RP. Native speakers of RP make extensive use of Elision, Assimilation, Smoothing and other special-context variants, particularly of course in informal contexts; adoptive RP speakers tend to avoid them" (1982: 284). 'Informal and allegro' features are conspicuously absent from the voice that Ninnette puts on when she pulls her funny face.

${ }^{24}$ Indeed, when Ninnette goes on to point to "four things pokin' out" of Joanne's jacket (lines 5053), there's a further striking parallel with Stallybrass and White's claim that "grotesque realism images the body as multiple, bulging, over- or under-sized, protuberant and incomplete" (1996: 9). 
youngsters' 'Imaginary', in a zone where 'ideology and fantasy conjoin' (Stallybrass and White 1996: 25).

This evidence of an extravagant grotesque is the first element in Extract 6 that helps to deepen our sense of what social class might mean for these youngsters, looking beyond speech act notions of 'meaning' and potentially destabilising the idea of a rational, tactical actor in control. The second aspect worth emphasising is the pre-eminence of corporeality in Ninnette's performance. ${ }^{25}$ As we've have seen, many cultural analysts point to the way in which classed notions of high-low extend to representations of the body, and indeed in my own data, it was the fact that sexuality and bodily matters were often thematically at issue in posh and Cockney stylisations that allowed us to speak of the high-low cultural semantic. Left like that, though, it might still be possible to construe the relationship as just that - as a semantic correlation, a cognitive pattern linking linguistic, cultural and social stereotypes. What Extract 6 attests is that beyond its verbal articulation, class-marked semiotic stylisation could also involve vigorous physical enactment.

This is hardly a startling discovery. The intimate enactive relationship between social class and the body is spelt out in Bourdieu's notion of hexis (1977: 660-663, 1991), and there are obviously substantial traditions describing visual, physical and material semiosis in (micro-)ethnography and video-based interaction analysis (e.g. McDermott et al 1978; Goodwin \& Goodwin 2001). Even so, there is quite a deep-seated logo-centric bias in linguistics and discourse analysis (Finnegan 1998), and within this, it would be easy to treat accent just as a surface-level phonological resource differentially available in the later stages of utterance production to people in specific socio-geographic locales. ${ }^{26}$ In contrast, the evidence on stylisation fits more closely with the view that

"most knowledge, especially the knowledge involved in everyday practice, does not take a linear, logic-sentential form but rather is organised into highly complex and integrated networks or mental models, most elements of which are connected to each other in a great variety of ways. The models form conceptual clumps which are not language-like precisely because of the simultaneous multiplicity of ways in which information is integrated in them. These mental models are, what is more, only partly linguistic; they also integrate visual imagery, other sensory cognition, the

25 At this point, I'd like to acknowledge Jan Blommaert's unstinting insight, as well as Helga Kotthoff's supportive critique, which both pulled me out of the deep analytic ditch that I'd dug for myself in earlier versions of this paper.

26 This can also affects our view of the balance between agency and sensibility within class processes. When analysis concentrates primarily on the linguistic modality, as if there was the only one communicative channel in play, it is easy to overestimate the speaker's control and to imagine that their verbal stream commands the whole field of local semiosis. This is a problem, for example, in Bell's distinction between 'initiative' and 'responsive' style shifts (1984). Initiative shifts are defined as linguistic actions that introduce a new contextual frame, while responsive shifts follow prior changes in the situation. But it's difficult to maintain this distinction if visual communication is considered, since this often operates as a prelude to verbal action, 'enabling participants to both project and negotiate what is about to happen' (Duranti \& Goodwin 1992: 7). In this context, a purely verbal recording can be misleading, and what looks like an initiation on audio-tape may actually be responding to contexts proposed on another semiotic level (see also Auer 1992: 4-21). 
cognitive aspects of learned practices, evaluations, memories of sensations, and memories of typical examples" (Bloch 1998: 24-25) ${ }^{27}$

In Extract 1, we could hear the parody of Mr Alcott being staged physically as well as verbally (line 6-18), and even in episodes where bodily articulations of dialect remain obscure due to our reliance on audio-recordings, moments of heightened performance involved fluent, spontaneous compositions in which a mix of vocal, generic, linguistic and cultural cues and images were clustered (cf Bauman [1975] 2001). From the high-low contrast reproduced across these posh and Cockney performances, we can see that they were, in Irvine's terms, part of an "ideologically mediated... system of distinction", composed of "contrasts, boundaries, and commonalities" (2001: 22). But rather than simply being phonological or linguistic units, the emic components comprising this system are distinctive integrations of - minimally - dialect, mode of speech, preoccupation and demeanour, which "crosscut... communicative and behavioural modalities and integrate... them thematically" (Irvine 2001: 23; Coupland 2001: 348).

Summing up the overall significance of Extract 6, we can regard it as an extreme case forcing us towards an interpretive idiom that is actually relevant to a great many of the episodes in my dataset. With other episodes, we might just be able to scrape by with notions like strategy, appropriateness and calculable impacts, but these signally fail with Extract 6, which insists instead that we engage with the aesthetic, a convenient umbrella term to stand, among other things, for the processes discussed in this Section. ${ }^{28}$ Exactly how the aesthetic should best be theorised can be left open, although fantasy, emotion, psychic interiority, physical activity, and sensory atunement to the material setting all now become potentially relevant for discussions of ideology (Downes 2000; Finnegan 2001; Knoblauch \& Kotthoff 2001; Irvine 2001). Overall, though, an orientation to the aesthetic helps to thicken our apprehension of what's entailed in the stylisation of posh and Cockney; the resonance and penetration of class-marked language gains depth; and referring back to Williams, we emerge with a more vivid view of high-low binaries can "saturat[e... people's] senses and assignments of energy" (1977: 109-110).

Extract 6, then, demands that we stretch our descriptive vocabulary, forcing a recognition of processes that bring linguistic analysis closer to the cultural analysts' discussions of class and subjectivity. In fact, if we add a little more Bakhtin to Williams, we can carry this further, across a much wider empirical base which also includes the Labovian evidence on routine variability.

\footnotetext{
${ }^{27}$ Within sociolinguistics, Garrett, Coupland and Williams have recently argued: "Because of the cultural constitution of dialect, speakers of different regional or social dialects engage with communicative tasks on a subtly different footing from speakers of others... There is a wide range of semantic and pragmatic phenomena on the fringe of dialect which sociolinguistics has not systematically addressed, having to do with rhetorical style, stance and implicature... People's responses to dialect are necessarily holistic. They are sensitive to the full range of social semiosis that any particular 'dialect performance' generates" (1999: 323; see also Coupland 1995; Becker 1995: 15; Tannen 1989: Ch 2; Bakhtin 1981: 293; Silverstein 1976: 51-52).

${ }^{28}$ Coupland 2001b: 10-12 usefully distinguishes between 'rational action' and 'praxis' theories of social action, the former being exemplified in politeness and accommodation theory, the latter in conversation analysis and ethnomethodology. At this juncture in my argument, it is rational action perspectives that look particularly inadequate.
} 


\section{The posh-Cockney complex as 'internally persuasive'}

As characterised in Section 1, discourse-oriented sociolinguistics tends to speak of situated agents, acts and resources, thinking in terms of a controlling subject who selects items from the linguistic repertoire according to his/her rhetorical purpose. Some of the instances of posh and Cockney stylisation in my corpus could be quite easily interpreted within a strategic-acts-of-identity perspective - in Extract 1, for example, the girls' own selfpositioning as 'principals' (Goffman 1974: Ch 13) was clearly quite distinct from the parodic 'figure' of Mr Alcott that they created with exaggerated posh. But elsewhere, it was often much less obvious where the speaker positioned their 'real' selves in relation to the voices they were using. ${ }^{29}$ In Extract 4, surely what mattered in Joanne's "Ninnette, Ricky's here" was the piquancy of the conjunction of posh with sexual possibility? whether or not she endorsed or objected to social types associated with posh seems beside the point. Similarly, in Extract 5 ('buggaye'), does it make any sense to say that Joanne identified with posh, dis-identified with Cockney, or vice-versa? Overall in my data, the self-voice positioning was rather indeterminate.

We can find an illuminating interpretation of such indeterminacy in Bakhtin's account of 'internally persuasive discourse'. Bakhtin sees all utterances as intrinsically dialogical, shaped in the encounter with other people, but there are a range of different ways in which we can orient to language and speech of others. Sometimes, we address their discourse in ways that put a distance between them and ourselves (e.g. Extract 1), but at other times, the boundary is much harder to maintain and their discourse starts to permeate into our talk and thinking. Bakhtin uses the phrase 'internally persuasive' to describe such permeation, and he proposes that "in the everyday rounds of our consciousness",

\footnotetext{
"the internally persuasive word is half-ours and half-someone else's. Its creativity and productiveness consist in the fact that... it organises masses of our words from within, and does not remain in an isolated and static condition. It is not so much interpreted by us as it is further, that is, freely developed, applied to new material, new conditions; it enters into inter-animating relationships with new contexts... The semantic structure of an internally persuasive discourse is not finite, it is open...." (1981: 345-346)
}

Stylised posh and Cockney were certainly very open. As I have already partly indicated,

- ultra-posh and Cockney emerged at moments when in one way or another, participants were attending to issues of sexuality, territory, reason and emotion, demeanour and deportment

- they featured in sound-play, self-talk, response-cries, greeting, taunts, commands, rebukes and summonses

- they were used to address, mock and caricature teachers, to fetishise particular individuals and to portray a variety of social types.

\footnotetext{
${ }^{29}$ See Johnstone 1999 for a full discussion of this issue in relation to Southern-sounding US speech.
} 
Cockney and posh certainly weren't the only speech varieties performed by these kids, but they resonated across a far wider set of circumstances than anything I found when, for example, I looked at the way these youngsters messed around with German. ${ }^{30}$

In fact, though, it isn't simply their openness and capacity to combine with different situations that invite use to align posh and Cockney with Bakhtin's description of 'internally persuasive' language. As already mentioned in Section 2 (and outlined in Rampton 2001b: 85-87), preliminary findings from quantitative analysis of Labovian styleshifting in these youngsters' ordinary speech suggest that they moved up and down between Cockney and posh quite normally in their routine activity, sometimes becoming more vernacular and sometimes more standard, in line with the formality of the situation. In other words, we can suggest that these kids lived the intimate tension between posh and Cockney in their everyday talk - the standard-vernacular nexus was, we might say, "supple and dynamic to such an extent that [it was] literally... omnipresent in the context, imparting to everything its own specific tones" (Bakhtin 1981: 347).

Such routine style-shifting is of course different from the performative stylisation we examined in Sections 3, 4 and 6, ${ }^{31}$ but we find a clue to their relationship when Bakhtin says that from time to time, supple, dynamic, internally persuasive discourse "break[s] through to become a completely materialised thing" (1981: 347). These break-throughs, we can say, are the moments of stylisation - spontaneous moments when these youngsters were artfully reflexive about the dichotomous values that they tacitly obeyed in the variability of their routine speech, moments when they crystallised the high-low structuring principles that were influential but normally much more obscure in their everyday variability (see also Voloshinov 1973: 90-92; Bauman and Briggs 1990: 60; Rampton 2001b: 97-98). Returning to the formulations offered by Raymond Williams, ordinary style-shifting between posh and Cockney looks like evidence of the routinisation achieved in hegemony, "the saturation of the whole process of living... [by] the... dominance and subordination of particular classes" (1977: 109), while in performative stylisation on the other hand, we can see moments of what Bakhtin calls 'ideological becoming', ${ }^{32}$ and what Williams calls 'creative practice': Moments when tensions "at the very edge of semantic availability... active, pressing but not yet fully articulated" find "specific articulations - new semantic figures -... in material practice" $(1977: 130,134) .{ }^{33}$ In the data we have inspected

${ }^{30}$ With knock-about Deutsch, classroom conduct and control were almost invariably at issue, and youngsters generally only switched to German at moments when there was some kind of clash between what they were doing and what their teachers wanted them to do.

31 The difference is also noted in the Labovian variationists' distinction between 'markers' and 'stereotypes'.

32 "This process - experimenting by turning persuasive discourse into speaking persons - becomes especially important in those cases where a struggle against such images has already begun, where someone is striving to liberate himself from the influence of such an image and its discourse by means of objectification, or is striving to expose the limitations of both image and discourse" (Bakhtin 1981: 348).

${ }^{33}$ Although she does not provide extensive empirical documentation, this point is also made very clearly in Eckert's theoretical rationale: "Part of developing an achieved place in the world is an increasing sense of the self as a commodity on the social market. In some very important sense, social development involves a process of objectification, as one comes to see oneself as having value in a marketplace... People 
(though not necessarily elsewhere in my dataset [Rampton 2001b]), there is little to suggest that these youngsters were really trying to liberate themselves from the cultural semantic that posh and Cockney were associated with, or that they were struggling to formulate alternatives to the equation of posh with high/ mind/ reason and of Cockney with low/body/emotion. But we can at least suggest that through the processes of objectification which highlighted these symbolic associations, stylisation partially denaturalised this pervasive cultural hierarchy, and disrupted its authority as "doxa", as an interpretive frame that that was "accepted undiscussed, unnamed, admitted without scrutiny" (Bourdieu 1977: 169-170; Eckert 2000: 14,43; Coupland 2001a: 370-372; Rampton 1995b: 508, 2001b).

\section{Summary and conclusions}

Three relationships need to be considered in this conclusion. These are the relationships between:

a) interactional discourse analysis and cultural studies (at least as I've typified them);

b) interactional and variationist sociolinguistics; and

c) the description of language and class in this paper and wider debates about social class in late modernity.

For (a), I took as a point of departure the micro-discursive analysis of particular episodes in which youngsters put on exaggerated posh and Cockney accents, and I tried to use these empirical data to explore ways in which sociolinguistics might extend beyond accounts of situated agency to incorporate something of the cultural analyst's concern for subjectivity. The first step towards this entailed the identification of a binary built around contrasts of high-low, mind-body, reason and emotion. This emerged from an overview of the dataset as a whole, it has historic roots in English class society, and it certainly pointed towards the more enduring dimensions of socio-historically-shaped sensibility that interest cultural analysts. On its own, though, this cultural semantic looked rather schematic, addressing, so to speak, only the first term in William's notion of a 'structure of feeling' (i.e. structure). When we confronted the grotesque in Extract 6, however, it became impossible to neglect the kinds of unreason and corporeality we associate with 'feeling', and this then led to retrospective recognition of the multi-sensory expressiveness of all the situated performances under review. The cultural semantic now looked a lot more 'lived', and in the end, rather than just treating posh and Cockney as communicative resources that speakers used to help express their stance on issues to do with sexuality, social rapport, physical demeanour etc, we reached a point where there was an empirical case for saying that these two dialects were actually integral elements in the way these youngsters experienced and made sense of such concerns.

call upon symbolic material of all kinds to mark their progress... The negotiation of meaning of these symbols becomes overt only when aspects of meaning become reified - when they become touchstones, or landmarks, in the process of construction. At that point, speakers can point to social meaning - they can identify others as jocks or burnouts, as elite or working-class, educated or not, prissy or tough" $(2000: 14,43)$. 
In terms of its methodological implications overall, this journey from 'doing' (and 'doing being') to 'being' (and the 'being doing') suggests that potentially, pragmatics and interaction analysis can provide powerful tools for describing the stressed interchange between consciousness and communication, for tracing, for example the movement between inner and outer experience that is crucial in Williams' notion of creative practice. ${ }^{34}$ But to do so, there needs from the start to be theoretical space for the kinds of experience that Williams identifies with practical consciousness, where "the tension between received interpretation and practical experience... is often an unease, a stress, a displacement, a latency: The moment of conscious comparison not yet come, often not even coming" (1977: 130). ${ }^{35}$ This is by definition very difficult to chart analytically, though fine-grained discourse analysis of unconscious communication patterns, multi-modal accounts of sensory experience in the material environment, and/or theories of psychic interiority may all have insights to offer. But to the extent that it is distinguished by a concern for the 'ineffable' - for the prearticulate and inarticulable - maybe the most rudimentary requirement is an orientation to the aesthetic dimension of communication.

What of (b) - the relationship between interactional and variationist sociolinguistics?

Evidence on routine quantitative style-shifting provided important support for the idea that posh and Cockney were inseparably bound into a binary symbolic and experiential nexus that was foundational in these young Londoners' practical class consciousness. In its commitment to distributional analysis, variationist sociolinguists have been more effective than interactionists in picking up on the exterior symptoms of social-class-as-aninternally-persuasive-cultural-semantic, and following others (Bourdieu, Woolard, Eckert, Irvine), I have cited both Labovian style-shifting and speech evaluation research as warrants for linking posh and Cockney to the dualisms identified by cultural analysts. But in other respects, it requires interactionist research to uncover the processes generating the product distributions detected by variationists. As noted in Section 1, quantitative methods can tell us little about the expressive practices involved in 'ideological becoming' (about the ways in which speakers objectify hegemonic structures of feeling in the situated contingencies of material practice), and we can criticise speech evaluation research for the rather sterile impersonality of the classed dualisms which get reported so consistently. In contrast, in Joanne's apostrophe to Ricky in Extract 4, in Ninnette's funny-eyes grotesque in Extract 6 , and in a host of other incidents, we can see that these dualisms feed very localised performances with resonant aesthetic effects. To quote Skeggs again, there can be "pleasures and [not just] pain associated with gender, class and sexuality" (1997: 10).

For substantive conclusions about the links between this paper and wider debates about social class in late modernity ([c]), it is first worth emphasising that class analysis obviously involves a massive set of complex issues that extend far beyond the concern here with language and class identity. And secondly, even within the narrow purview of this paper, I' $m$ limited by the fact that there is much more to be said about, for example, (i) the

\footnotetext{
${ }^{34}$ Williams himself outlines a very sophisticated pragmatic apparatus in Part III of Marxism and Literature (1977), anticipating a number of more recent developments.

35 See Billig 1999 for a much fuller articulation of this position; also (though on different lines), Rampton 2002
} 
school and the individual kids themselves, (ii) the stylisation of posh and Cockney in lessons, and (iii) the part that class stylisations played in the negotiation of other axes of social differentiation - sexuality, gender, ethnicity. ${ }^{36}$ Even so, there is enough here to take issue with the view that in recent years, social class identities have lost much of their significance.

In the first instance, we have seen that

i) the tension between posh and Cockney was pervasive in these kids' routine styleshifting;

ii) they dramatised this in a wide range of performative stylisations, on average about once every half-hour;

iii) these performances took place in relatively symetrical interaction between peers, not just in pupil-teacher exchanges where at a micro-political level, one might expect to find a clash of class interests;

iv) they inserted classed voices into performances of the fantastical grotesque, which suggests that class penetrated quite 'deep' into their imaginary.

As I have already admitted, there wasn't much evidence of explicit, propositionally elaborate class consciousness among my informants, but the disappearance of class from established ideologies didn't turn it into a non-issue for these kids. Instead, it was repeatedly drawn into the 'upper strata of behavioural ideology' in the small-scale acts of political 'crystallisation' achieved in stylisation (Voloshinov 1973: 90-92).

Second, these youngsters' parents often came from other countries, using English as very much a second language, and so we can't say that these kids were implicated in the inter-generational reproduction of an English working class family culture (Willis 1976: 191). Even so, their stylisations of posh and Cockney amounted to far more than a superficial engagement with the class dynamics of English society, to far more than ironic impersonations performed by peripheral spectators. Of course the more specific meanings of class vary interactionally, biographically and historically, ${ }^{37}$ but within this, these youngsters seemed to be very full participants in the "emotive intimacies of class" (Reay 1998: 265).

Lastly, it is often said that class has been undermined by key processes associated with globalisation and late-modernity - by the fracturing and pluralisation of identities, by the pre-eminence of the individual as consumer, and by a loss of faith in the 'grand narratives' and totalising theories of modernism (Bradley 1996; Comaroff \& Comaroff 1992; 'Introduction', this volume). It would be difficult to claim that either the data or the

\footnotetext{
36 The analysis of (iii), for example, will provide some insight into just how powerful the class semantic actually is - just how far the posh-Cockney lingua-cultural complex has 'recursively colonised' other social divisions, providing these youngsters with a dominant frame for interpreting the inequalities associated with differences of e.g. male-female, urban-rural etc. (see Irvine 2001). Indeed, in principle it would be possible to extend such an analysis by comparing the 'work' done by posh-\&-Cockney stylisation with the situations where youngsters styled 'foreignness', 'Indian English', creole and so forth (Rampton 1995).

${ }^{37}$ On the changing meanings of class in contemporary multi-ethnic settings in Britain, see e.g. Brah 1996: 209; Gilroy 1987: 194-197; Back 1996: 123.
} 
analysis in this study have been shielded from these processes. The informants in the research were young people, who according to sociologists "are especially responsive to... the cultural changes discerned by postmodernists" and who, as a result, are most likely to be affected by "the decline of class awareness" (Bradley 1996: 77). The field site was also very far from being a traditional cultural enclave: Youngsters came to the school from many different parts of London, approximately a third of them were from refugee and asylumseeking families, and in Ninnette's class of 30, they spoke about a dozen different languages. And methodologically, the research has been micro-analytic, attentive to unpredictable contingencies of situated activity, and quite sympathetic to the ontological assumptions of post-modernism (Rampton 2001a; Harris \& Rampton 2002). But despite these notionally inauspicious conditions, adolescent stylisations repeatedly foregrounded social class as a frame relevant to the flux of experience, and when these occasions are taken together, it would be very hard indeed to ignore the hegemonic impress of a polarising cultural binary that has been long and intimately linked to class systems both in Britain and elsewhere.

\section{References}

Abercrombie, N., A. Warde, R. Deem, S. Penna, K. Soothill, J. Urry, A. Sayer, and S. Walby (2000) Contemporary British Society. 3rd Edition. Oxford: Polity Press.

Antaki, C. (1998) Identity ascriptions in their time and place: 'Fagin' and 'the terminally dim'. In Antaki and Widdicombe (eds.), pp. 71-86.

Antaki, C. and S. Widdicombe (1998) Identity as an achievement and as a tool. In Antaki and Widdicombe (eds.), pp. 1-14.

Antaki and Widdicombe (eds.) (1998) Identities in Talk. London: Sage.

Back, L. (1996) New Ethnicities and Urban Culture. London: UCL Press.

Bakhtin, M. (1968) Rabelais and his World. Cambridge, Mass: M.I.T. Press.

Bakhtin, M. (1981) The Dialogic Imagination. Austin: Texas University Press.

Bakhtin, M. (1984) Problems in Dostoevsky's Poetics. Minneapolis: University of Minnesota Press.

Bauman, R. [1975] (2001) Verbal art as performance. In A. Duranti (ed.), Linguistic Anthropology: A Reader. Oxford: Blackwell, pp. 165-188.

Bauman, R., and C. Briggs (1990) Poetics and performance as critical perspectives on language and social life. Annual Review of Anthropology 19: 59-88.

Bell, A. (1984) Language style as audience design. Language in Society 13.2: 145-204.

Billig, M. (1999) Freudian Repression. Cambridge: Cambridge University Press.

Bloch, M. (1998) How We Think They Think: Anthropological Approaches to Cognition, Memory, and Literacy. Colorado: Westview Press. 
Blom, J.P., and J. Gumperz (1972) Social meaning in linguistic structure: Codeswitching in Norway. In J. Gumperz \& D. Hymes (eds.), Directions in Sociolinguistics. Oxford: Blackwell, pp. 407-34.

Bourdieu, P. (1977) Outline of a Theory of Practice. Cambridge: Cambridge University Press.

Bourdieu, P. (1991) Language and Symbolic Power. Oxford: Polity Press.

Bradley, H. (1996) Fractures identities: Changing patterns of inequality. Cambridge: Polity Press.

Brah, A. (1996) Cartographies of Diaspora. London: Routledge.

Cameron, D. (1992) Demythologising sociolinguistics: Why language does not reflect society. In J. Joseph \& T. Taylor (eds.), Ideologies of Language. London: Routledge, pp. 79-96.

Clark, J.T. (2003) Abstract inquiry and the patrolling of black/white borders through linguistic stylisation. In R. Harris \& B. Rampton (eds.), Language, Ethnicity and Race: A Reader. London: Routledge.

Cohen, P. (1988) The perversions of inheritance: Studies in the making of multi-racist Britain. Multi-Racist Britain. P. Cohen, H. Bains, S. Basingstoke, Macmillan, pp. 9-120.

Comaroff, J.L., and J. Comaroff (1992) Ethnography and the Historical Imagination. Colorado: Westview Press.

Coupland, N. (1995) Pronunciation and the rich points of culture. In J. Windsor-Lewis (ed.), Studies in English and General Phonetics: In Honour of J.D. O'Connor. London: Routledge, pp. 310-319.

Coupland, N. (2001a) Dialect stylisation in radio talk. Language in Society 30.3: 345-376.

Coupland, N. (2001b) Introduction: Sociolinguistic theory and social theory. In N. Coupland et al (eds.), pp. $1-26$.

Coupland, N. (2001c) Age in social and sociolinguistic theory. In N. Coupland et al (eds.), pp. 185-211.

Coupland, N., S. Sarangi, and C. Candlin (eds.) (2001) Sociolinguistics and Social Theory. London: Longman.

Crowley, T. (1989) The Politics of Discourse. London: Routledge.

Cruttenden, A. (1986) Intonation. Cambridge: Cambridge University Press.

Downes, W. (2000) The language of felt experience: Emotional, evaluative, intuitive. Language and Literature. 9.2: 99-121.

Drew, D. (1987) Po-faced receipts of teases. Linguistics 25: 219-253.

Eagleton, T. (1984) The Function of Criticism. London: Verso.

Eckert, P. (2000) Linguistic Variation as Social Practice. Oxford: Blackwell.

Finnegan, R. (2001) 'Not the message': Media, meanings and magicality. In H. Knoblauch \& H. Kotthoff (eds.), Verbal Art across Cultures. Tübingen: Gunter Narr Verlag, pp. 33-62.

Foley, D. (1990) Learning Capitalist Culture. Philadelphia: University of Pennsylvania Press.

Gal, S. (1989) Language and political economy. Annual Review of Anthropology. 18: 345-367. 
Gal, S. [1991] (2001) Language, gender and power: An anthropological review. In A. Duranti (ed.), Linguistic Anthropology: A Reader. Oxford: Blackwell, pp. 420-430.

Garrett, P., N. Coupland, and A. Williams (1999) Evaluating dialect in discourse: Teachers' and teenagers' responses to young English speakers in Wales. Language in Society 28.3: 321-354.

Giles, H., and P. Powesland (1975) Speech Style and Social Evaluation. New York: Academic Press.

Giles, H., and E. Ryan (1982) Prolegomena for developing a social psychological theory of language attitudes. In E.B. Ryan, \& H. Giles (eds.), Attitudes to Language Variation. London: Edward Arnold, pp. 208-223.

Gilroy, P. (1987) There Ain't No Black in the Union Jack. London: Hutchinson.

Goodwin, M., and C. Goodwin [2000] (2001) Emotion within situated activity. In A. Duranti (ed.h,inguistic Anthropology: A Reader. Oxford: Blackwell, pp. 239-257.

Goffman, E. (1974) Frame Analysis. Boston: Northeastern University Press.

Goffman, E. (1981) Forms of Talk. Oxford: Blackwell.

Gumperz, J. (1982) Discourse Strategies. Cambridge: Cambridge University Press.

Hanks, W. (1996) Language and Communicative Practice. Colorado: Westview Press.

Harris, R., and B. Rampton (2002) Creole metaphors in cultural analysis: On the limits and possibilities of (socio-)linguistics. Critique of Anthropology 22.1: 31-51.

Hey, V. (1997) Northern accent and Southern comfort: Subjectivity and social class. In P. Mahony \& . C. C. Zmroczek (eds.), Class Matters: 'Working Class' Women's Perspectives on Social Class. London: Taylor \& Francis, pp. 140-51.

Holland, D., D. Skinner, W. Lachicotte, and C. Cain (1998) Identity and Agency in Cultural Worlds. Massachusetts: Harvard University Press.

Hudson, R.A. (1996) Sociolinguistics: Second Edition. Cambridge: Cambridge University Press.

Hutchins, E. (1993) Learning to navigate. Understanding Practice. S. Chaiklin, J. Lave. Cambridge: Cambridge University Press, pp. 35-63.

Hymes, D. (1996) Ethnography, Linguistics, Narrative Inequality. London: Taylor \& Francis.

Irvine, J. (2001) 'Style' as distinctiveness: The culture and ideology of linguistic differentiation. In P. Eckert \& J. Rickford (eds.), Style and Sociolinguistic Variation. Cambridge: Cambridge University Press, pp. 21-43.

Johnstone, B. (1999) Uses of Southern-sounding speech by contemporary Texas women. Journal of Sociolinguistics 3.4: 505-522.

Knoblauch, H., and H. Kotthoff (2001) The aesthetics and proto-aesthetics of communication. In H. Knoblauch \& H. Kotthoff (eds.), Verbal Art across Cultures. Tübingen: Gunter Narr Verlag, pp. 7-32.

Labov, W. (1972) Sociolinguistic Patterns. Oxford: Blackwell.

Lambert, W. (1972) A social psychology of bilingualism. Sociolinguistics. J. Pride, J. Holmes. Harmondsworth: Penguin, pp. 336-349. 
LePage, R, and A. Tabouret-Keller (1985) Acts of Identity. Cambridge: Cambridge University Press.

Levinson, S. (1983) Pragmatics. Cambridge: Cambridge University Press.

Lippi-Green, R. (1997) English With An Accent. London: Routledge.

McDermott, R., K. Gospodinoff, and J. Aron (1978) Criteria for an ethnographically adequate description of concerted activities and their contexts. Semiotica 24.3/4: 245-275.

Milroy, L. (1980) Language and Social Networks. Oxford: Blackwell.

Milroy, J. (1992) Linguistic Variation and Change. Oxford: Blackwell.

Milroy, L, and J. Milroy (1992) Social network and social class: Toward an integrated sociolinguistic model. Language in Society 21.1: 1-26.

Moerman, M. (1988) Talking Culture. Philadelphia: University of Pennsylvania Press.

Mugglestone, L. (1995) Talking Proper. Oxford: Clarendon Press.

Ortner, S. (1991) Reading America: Preliminary notes on class and culture. In R. Fox (ed.), Recapturing Anthropology: Working in the Present. Santa Fe: School of American Research Press, pp. 164-189.

Rampton, B. (1995) Crossing: Language and Ethnicity among Adolescents. London: Longman.

Rampton, B. (1995b) Language crossing and the problematisation of ethnicity and socialisation. Pragmatics 5.4: $485-514$.

Rampton, B. (1998) Language crossing and the redefinition of reality. In P. Auer (ed.), Codeswitching in Conversation. P. Auer. London: Routledge, pp. 290-317.

Rampton, B. (1999a) Crossing. Special issue of Journal of Linguistic Anthropology entitled "A Lexicon for the Millenium" 9.1-2: 54-56.

Rampton, B. (1999b) Deutsch in inner London and the animation of an instructed foreign language. Journal of Sociolinguistics 3.4: 480-504.

Rampton, B. (2001a) Language crossing, 'Crosstalk' and cross-disciplinarity in sociolinguistics. In N. Coupland, S. Sarangi \& C. Candlin (eds.), Sociolinguistics and Social Theory. London: Longman, pp. 261296.

Rampton, B. (2001b) Critique in interaction. Critique of Anthropology 21.1: 83-107.

Rampton (2002) Ritual and foreign language practices at school. Language in Society 31.4: 491-526.

Reay, D. (1998) Rethinking social class: Qualitative perspectives on class and gender. Sociology 32.2: 259275.

Sapir, E. [1931] (1949) Communication. In D. Mandelbaum (ed.), Edward Sapir: Selected Writings in Language, Culture and Personality. Berkeley: University of California Press, pp. 104-109.

Silverstein, M. (1976) Shifters, linguistic categories, and cultural description. In K. Basso \& H. Selby (eds.), Meaning in Anthropology. Albuquerque: University of New Mexico, pp. 11-55.

Scott, J. (1990) Domination and the Arts of Resistance. New Haven: Yale University Press. 
Shipley, J.T. (ed.) (1970) Dictionary of World Literary Terms. London: George Allen \& Unwin.

Skeggs, B. (1997) Formations of Class and Gender. London: Sage.

Sperber, D. (1975) Rethinking Symbolism. Cambridge: Cambridge University Press.

Stallybrass, P., and A. White (1996) The Politics and Poetics of Transgression. London: Methuen.

Thompson, E.P. (1963) The Making of the English Working Class. London: Penguin.

Thompson, E.P. (1978) The Poverty of Theory and Other Essays. London: Merlin.

Trudgill, P. (1983) On Dialect. Oxford: Blackwell.

Voloshinov, V. (1973) Marxism and the Philosophy of Language. Cambridge, Mass: Harvard University Press.

Urcioli, B. (1996) Exposing Prejudice. Colorado: Westview Press.

Wells, J.C. (1982) Accents of English 2: The British Isles. Cambridge: Cambridge University Press.

Williams, R. (1977) Marxism and Literature. Oxford: Oxford University Press.

Willis, P. (1976) The class significance of school counter-culture. In M. Hammersley, \& P. Woods (eds.), The Process of Schooling. London: Routledge \& Kegan Paul, pp. 188-200.

Willis, P. (1977) Learning to Labour. Farnborough: Saxon House.

Woolard, K. (1985) Language variation and cultural hegemony: Toward an integration of sociolinguistic and social theory. American Ethnologist 12: 738-48.

\section{Transcription conventions}

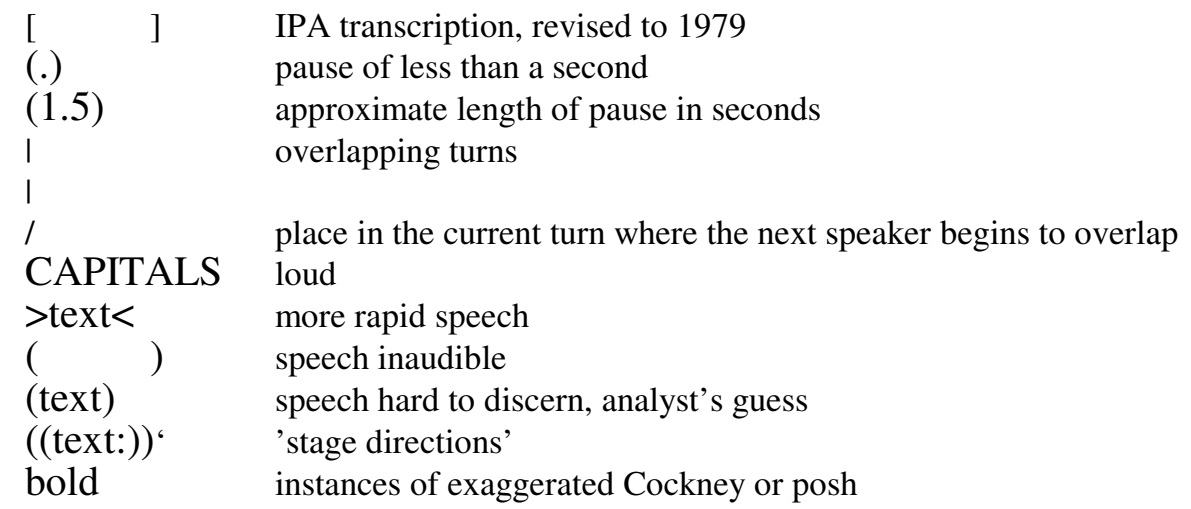

